\title{
PMMA-sepiolite nanocomposites as new promising materials for the production of nanocellular polymers
}

\author{
Victoria Bernardo*, Judith Martín-de León, Ester Laguna-Gutiérrez, \\ Miguel Ángel Rodríguez-Pérez
}

Cellular Materials Laboratory (CellMat), Condensed Matter Physics Department, University of Valladolid, Campus Miguel Delibes, Paseo de Belén n7, 47011 Valladolid, Spain

\section{A R T I C L E I N F O}

\section{Keywords:}

Nanocellular polymer

Nanocellular foam

Gas dissolution foaming

Nanoparticles

Sepiolites

PMMA

\begin{abstract}
A B S T R A C T
In this work, a new system based on poly(methyl methacrylate) (PMMA) sepiolite nanocomposites that allow producing nanocellular polymers by using the gas dissolution foaming technique is described. Nanocomposites with different nanoparticle types and contents have been produced by extrusion. From these blends, cellular materials have been fabricated using the so-called gas dissolution foaming method. An extensive study of the effect of the processing parameters (saturation pressure and foaming temperature) on the cellular materials produced has been performed. Results showed that among the three sepiolites used, only those modified with a quaternary ammonium salt are suitable for being used as nucleating agents in PMMA. With these nanoparticles bimodal cellular polymers, with micro and nanometric cells, have been produced. Cell sizes in the range of $300-500 \mathrm{~nm}$ and cell densities of the order of $10^{13}-10^{14} \mathrm{nuclei} / \mathrm{cm}^{3}$ have been obtained in the nanocellular region. A foaming temperature of $80{ }^{\circ} \mathrm{C}$ and a wide range of saturation pressures (between 10 and $30 \mathrm{MPa}$ ) and low particle contents (between 0.5 and $1.5 \mathrm{wt} \%$ ) allow obtaining these materials. Furthermore, it has been found that cell size in the nanometric population can be controlled by means of the particles content; a reduction in the cell size is obtained when the particles content increases. Finally, results indicate that an increase in the foaming temperature leads to cellular nanocomposites with lower relative densities (below 0.21 ) and larger cell sizes (above $450 \mathrm{~nm}$ ).
\end{abstract}

\section{Introduction}

Nanocellular polymers are cellular materials in which the gaseous phase is confined in nanometric pores (cell size smaller than $500 \mathrm{~nm}$ ). It has been recently shown that these materials have better mechanical properties than those of conventional cellular materials or microcellular materials [1-3]. This fact has been attributed to the confinement of the polymer in very thin cell walls and the large surface area present in these structures [4]. In addition, the nanometric cell size implies a significant reduction of the thermal conductivity due to the decrease of the heat conduction transfer through the gaseous phase (Knudsen effect) [5,6], which results in materials with thermal conductivities lower than that of conventional cellular materials. Moreover, open cell nanocellular polymers could be used as membranes for micro and ultrafiltration of particles $[7,8]$ and they can be employed in catalysis and sensors as well [9]. As a consequence of this interesting combination of properties, nanocellular materials have aroused great interest in the scientific community.

\footnotetext{
* Corresponding author.

E-mail address: vbernardo@fmc.uva.es (V. Bernardo).
} 
Much of the research in this area is focused on the development of new and improved nanocellular polymers with scalable-up production routes. One of the most promising techniques to produce nanocellular polymers is the so-called gas dissolution foaming method, where $\mathrm{CO}_{2}$ is normally used as blowing agent. This technology allows producing large samples using a green solvent $\left(\mathrm{CO}_{2}\right)$ that can be removed without leaving neither residues nor pollutant compounds. However, the production of nanocellular materials using homogeneous systems usually requires extreme saturation conditions so as to obtain the high cell nucleation densities required. For instance, for polycarbonate (PC) [10], polysulfone (PSU) [11] and poly(methyl methacrylate) (PMMA) [12]. Guo and coworkers [12] obtained cell sizes as low as $20 \mathrm{~nm}$ working with extremely low saturation temperatures $\left(-30^{\circ} \mathrm{C}\right)$. Martin-de Leon et al. [13] obtained low density nanocellular PMMA foams with relative densities varying between 0.25 and 0.4 using high saturation pressures (30 MPa). Bernardo et al. [14] showed that high-performance thermoplastic polyphenylsulfone (PPSU) could be used to produce nanocellular polymers at saturation pressures higher than $15 \mathrm{MPa}$. The use of high pressures and low temperatures implies higher energy consumption and higher $\mathrm{CO}_{2}$ spending. Besides, diffusivity extremely decreases for negative temperatures [10,15], and thus under these conditions high saturation times are needed. All these drawbacks limit the of mass production and therefore, finding new production routes using not demanding processing conditions is nowadays a priority in the development of the nanocellular polymers field.

In this respect, an alternative approach consists on favouring nucleation by the addition of appropriate nucleating species that provide heterogeneous surfaces on which the nucleation energy barrier is lowered. With the addition of this second phase heterogeneous nucleation starts to play an important role during the process [16]. Taking advantage of heterogeneous nucleation, nanocellular polymers can be produced by using low saturation pressures and conventional saturation temperatures, as nucleation is mainly controlled by the disperse phase (nanoparticles $[17,18]$ and/or secondary phases in nanostructured polymers $[8,19-21]$ ) and not by the amount of gas dissolved into the sample. Besides, the use of a second phase to promote nucleation can help to obtain a more uniform cell size distribution [22].

The addition of nanoparticles to enhance the nucleation density has been investigated in the development of micro and nanocellular materials. A wide variety of polymeric matrices and nanoparticles have been used for this purpose. Spherical nanosilicas [22-24] and layered montmorillonite-type nanoclays [18,25,26] have been proved to be suitable nucleating agents in different polymeric matrices. For instance, in the work of Siripurapu et al. [27] ultraporous PMMA films were produced using silica particles. A $12 \mathrm{wt} \%$ of these particles led to a reduction in the cell size from 10 to almost $1 \mu \mathrm{m}$. Yang and coworkers [24] used spherical ordered mesoporous silica particles to increase the cell density in PMMA. The addition of a $5 \mathrm{wt} \%$ of these particles reduced the pore size from the micro $(1.62 \mu \mathrm{m})$ to the nanometric range $(660 \mathrm{~nm})$. Costeux et al. [17] enhanced the cell nucleation density three orders of magnitude by adding silica nanoparticles to a PMMA matrix. With filler contents below 0.5 wt $\%$ nanocellular materials with cell sizes of $100 \mathrm{~nm}$ and cell densities exceeding $10^{16}$ cells $/ \mathrm{cm}^{3}$ were obtained. Urbanczyk et al. [26] shown the effect of montmorillonite-type nanoclays in the production of poly(styrene-co-acrylonitrile) (SAN) micro and nanocellular polymers. In particular, they obtained cell sizes below the micron and relative densities around 0.5 with $3 \mathrm{wt} \%$ of nanoparticles.

Sepiolites have been shown to be appropriate inorganic nanofillers for polymers because of their diameter dimensions at the nanoscale and the high aspect ratio of this fibrous clay. With the appropriate surface treatment these particles can be well dispersed in different types of polymers, including PMMA [28,29]. It has been reported that the addition of sepiolites can improve some properties of the polymeric matrix. For instance, they produce a flame retardant effect in polypropylene (PP) [30]. They can also act as a nucleating agents in the crystallization of PP [31]. In epoxy nanocomposites, an improvement in impact and flexural strength is observed when sepiolites are added [32]; whereas in PMMA, sepiolites lead to an improvement in the thermal stability [33]. However, there are few works dealing with the production of cellular materials containing sepiolites. In the patent of Igualada et al. [34] PS/sepiolite cellular materials were fabricated by extrusion foaming using $\mathrm{CO}_{2}$ as physical blowing agent. Results of this patent show that sepiolites produce better nucleation effects than conventional fillers like talc. In the work of Santaren et al. [35] PS/ sepiolite microcellular materials were produced using a gas dissolution foaming process. Cell density was increased two orders of magnitude after the addition of a $5 \mathrm{wt} \%$ of sepiolites, whereas cell size decreased from 27 to $4 \mu \mathrm{m}$. Besides, the addition of sepiolites reduced the thermal conductivity and improved the mechanical properties of the cellular materials. Sepiolites have also been used to produce gelatin nanocomposite based cellular materials [36]. A 9\% of sepiolite was found to reduce the cell size from 160 to $100 \mu \mathrm{m}$ and to increase the Young's modulus from 1.5 MPa to $6 \mathrm{MPa}$. In the work of Killen et al. [37] porous poly(vinyl alcohol) was produced using sepiolites. Although the incorporation of sepiolites increased the mean pore size, the tensile strength, modulus and energy at break were improved with the addition of sepiolite contents up to a $6 \mathrm{wt} \%$. In all the previously mentioned works sepiolites were used to produce microcellular polymers.

This work aims to be the first report about the nucleating effect of sepiolites in the production of nanocellular PMMA. Besides, as far as the author knows, there are not works dealing with the production of nanocellular materials using needle-shaped nanoparticles with one dimension in the micrometric range. In particular, solid nanocomposites based on PMMA with different types of sepiolites and with different concentrations have been produced by extrusion. The dispersion of the particles in the blends has been evaluated by image analysis and shear rheology. Then, the foaming behaviour of these systems has been extensively analysed by performing experiments at different saturation and foaming conditions. In the end, one specific grade of the sepiolites analysed have been found to be a very promising nucleating agent for the production of nanocellular PMMA using low saturation pressures and room temperature as saturation conditions. 
Table 1

Formulations used in this work.

\begin{tabular}{lll}
\hline Material ID & Sepiolite type & Sepiolite content (wt\%) \\
\hline PMMA & - & 0 \\
$0.5 \%$ S-N & S-N & 0.5 \\
$0.5 \%$ S-QAS & S-QAS & 0.5 \\
$0.5 \%$ S-S & S-S & 0.5 \\
$1 \%$ S-QAS & S-QAS & 1 \\
$1.5 \%$ S-QAS & S-QAS & 1.5
\end{tabular}

\section{Experimental}

\subsection{Materials}

Poly(methyl methacrylate) (PMMA) V 825T was kindly supplied by ALTUGLAS ${ }^{\circledR}$ International in the form of pellets with a density (p) of $1.18 \mathrm{~g} / \mathrm{cm}^{3}$ and a glass transition temperature $\left(\mathrm{T}_{\mathrm{g}}\right.$ ) of $114.5^{\circ} \mathrm{C}$ measured by DSC.

Sepiolites were provided by Tolsa S.A (Spain). These clays chemically correspond to hydrated magnesium silicates (formula $\left.\mathrm{Si}_{12} \mathrm{Mg}_{8} \mathrm{O}_{30}(\mathrm{OH})_{4}\left(\mathrm{OH}_{2}\right)_{4} \cdot 8 \mathrm{H}_{2} \mathrm{O}\right)$. Sepiolites present a needle-like morphology, with an average particle length ranging between 1 and $2 \mu \mathrm{m}$ and a diameter in the nanometric range (between 20 and $30 \mathrm{~nm}$ ) [38,39]. Three different sepiolites have been employed in this work: non-organically modified sepiolite (labelled from now on as S-N) and two superficially organomodified sepiolites. The first one has been modified with a quaternary ammonium salt (S-QAS) and the second one with a silane (S-S). The process to obtain and modify these particles can be found elsewhere $[29,35,40]$.

Finally, medical grade carbon dioxide $\left(\mathrm{CO}_{2}\right)$ (99.9\% purity) was used as blowing agent for the gas dissolution foaming experiments.

\subsection{Solid blends production}

Blends of PMMA and sepiolites in the desired proportions (Table 1) were compounded using a twin-screw extruder model COLLIN TEACH-LINE ZK 25T, with L/D of 24 and screw diameter of $25 \mathrm{~mm}$. All materials were dried in a vacuum oven at $50{ }^{\circ} \mathrm{C}$ during $12 \mathrm{~h}$ prior to compounding. The temperature profile set on the extruder was from $160{ }^{\circ} \mathrm{C}$ to $200{ }^{\circ} \mathrm{C}$ (in the die), increasing at intervals of $10{ }^{\circ} \mathrm{C}$, and the screw speed was $40 \mathrm{rpm}$. The produced blends were cooled in a water bath and pelletized. After drying the pellets for $2 \mathrm{~h}$ in a vacuum oven at $50^{\circ} \mathrm{C}$, each material was extruded again with the aim of dispersing homogenously the nanoparticles. The temperature profile and the screw speed remained the same.

In a second step the obtained pellets were compression moulded into solid sheets of $155 \times 75 \times 4 \mathrm{~mm}^{3}$ using a hot plate press provided by Remtex. The temperature of the press was fixed at $250{ }^{\circ} \mathrm{C}$. The materials were first molten without applying any pressure during $8.5 \mathrm{~min}$ and then they were compacted under a constant pressure of $2.2 \mathrm{MPa}$ for another minute. Finally, the sheets were cooled down at room temperature under the same pressure. All materials were first dried in an oven at $80{ }^{\circ} \mathrm{C}$ during $4 \mathrm{~h}$ before processing. Rectangular prims of $20 \times 20 \times 4 \mathrm{~mm}^{3}$ were cut from the sheet for the foaming experiments. In addition, cylindrical samples with a thickness of $1.5 \mathrm{~mm}$ and a diameter of $25 \mathrm{~mm}$ were prepared by compression moulding using the same procedure, and used later for the rheological measurements.

Neat PMMA was processed under the same conditions for the sake of comparison and it will be called from now on as PMMA.

Blends containing $0.5 \mathrm{wt} \%$ of the three types of sepiolites were produced with the aim of analysing the effect of the type of particle. Moreover, two additional blends, with the sepiolite S-QAS, at higher particle contents ( 1 and 1.5 wt $\%$ ) were also produced to analyse the influence of the particle content. The formulations used in this work are summarized in Table 1.

\subsection{Gas dissolution foaming experiments}

Foaming experiments were performed using a high pressure vessel (model PARR 4681) provided by Parr Instrument Company with a capacity of $1 \mathrm{~L}$. The maximum temperature and pressure reached by this device are $350{ }^{\circ} \mathrm{C}$ and $41 \mathrm{MPa}$, respectively. An accurate pressure pump controller (model SFT-10) provided by Supercritical Fluid Technologies Inc. controls automatically the pressure to keep the desired value. The vessel is equipped with a clamp heater of $1200 \mathrm{~W}$, and its temperature is controlled via a CAL 3300 temperature controller. With this set up a set of experiments has been performed using a two-step foaming process [41]. Firstly, samples were introduced in the pressure vessel under certain pressure and temperature conditions for the saturation stage. After saturation, pressure was abruptly released. Then samples were removed from the pressure vessel and immersed in a thermal bath at the desired foaming temperature. The time between the release of pressure and the immersion in the baths was 3.5 min.

Saturation temperature has been fixed at $25^{\circ} \mathrm{C}$ and saturation time was $20 \mathrm{~h}$ for all the experiments. Preliminary saturation tests were performed to prove that $20 \mathrm{~h}$ is enough time to achieve full saturation of $\mathrm{CO}_{2}$ in PMMA at all the pressures under study and for the thickness of the samples used. Two sets of experiments have been performed. Firstly the influence of the saturation pressure (and thus the amount of gas absorbed) has been evaluated by choosing three different saturation pressures: 10, 20 and $30 \mathrm{MPa}$. The pressure drop rates in these experiments were $15 \mathrm{MPa} / \mathrm{s}, 56 \mathrm{MPa} / \mathrm{s}$ and $100 \mathrm{MPa} / \mathrm{s}$, respectively. For this study, foaming has been 
carried out at $80^{\circ} \mathrm{C}$ during $2 \mathrm{~min}$. Secondly the effect of the foaming temperature has been analysed by fixing the saturation pressure to $10 \mathrm{MPa}$, varying the foaming temperature from $80{ }^{\circ} \mathrm{C}$ to $110{ }^{\circ} \mathrm{C}$, keeping, once again, 2 min as foaming time. It is important to remark that under these conditions $\left(25^{\circ} \mathrm{C}\right.$ and $\left.10-30 \mathrm{MPa}\right)$ the effective glass transition temperature of PMMA after gas absorption is below room temperature [20], so samples start to expand after being removed from the autoclave as soon as they reach room temperature. Nevertheless, the most of the expansion occurs in the thermal baths.

\subsection{Characterization}

\subsubsection{Density}

Density of the solid composites was measured with a gas pycnometer (Mod. AccuPyc II 1340, Micromeritics). Density of the corresponding cellular materials was determined with the water-displacement method based on Archimedes' principle. A density determination kit for an AT261 Mettler-Toledo balance has been used for this purpose. The solid skin of the samples was removed out with a polisher (model LaboPOl2-LaboForce3, Struers) by removing more than $200 \mu \mathrm{m}$ of each side before measuring their densities. In addition, foamed samples were left to desorb all $\mathrm{CO}_{2}$ before measuring the density. Relative density $\left(\rho_{\mathrm{r}}\right)$ has been calculated as the ratio between the cellular material density $\left(\rho_{\mathrm{f}}\right)$ and the density of the solid nanocomposite with the same chemical composition $\left(\rho_{\mathrm{s}}\right)$.

\subsubsection{Solid nanocomposites morphology}

The dispersion of the sepiolites in the polymeric matrix was qualitatively analysed using an ESEM Scanning Electron Microscope (QUANTA 200 FEG). Solid nanocomposites were prepared by cooling them in liquid nitrogen, fractured and finally coated with gold using a sputter coater (model SCD 005, Balzers Union).

\subsubsection{Dynamic shear properties}

It has been reported that dynamic shear measurements can be employed as a tool to analyse the dispersion of nanoparticles in polymeric matrices $[42,43]$. Besides, rheological properties are important in the analysis of the influence of the polymer viscosity into the nucleation and growing processes $[19,44]$. For these reasons, dynamic shear properties of all the nanocomposites were measured using a stress controlled rheometer, AR 2000 EX from TA Instruments. Measurements were performed at a temperature of $230{ }^{\circ} \mathrm{C}$ under nitrogen atmosphere using a parallel plates geometry of $25 \mathrm{~mm}$ in diameter and a gap of $1 \mathrm{~mm}$. Cylindrical samples with a thickness of $1.5 \mathrm{~mm}$ and a diameter of $25 \mathrm{~mm}$ were used for the experiments (Section 2.2).

When the sample is loaded the particles network is partially deformed. The initial state could be recovered again waiting a certain time. In order to define a well-controlled starting point for all the rheological experiments a time sweep was previously performed at a frequency of $1 \mathrm{rad} / \mathrm{s}$. This time sweep was conducted during $300 \mathrm{~s}$. Then, dynamic-mechanical experiments over an angular frequency range of $0.01<\omega<100 \mathrm{rad} / \mathrm{s}$ were performed for all the blends and the pure polymer. The same strain as that employed in the time sweep: $3 \%$ (within the linear viscoelastic response of the materials) was used. From these measurements three magnitudes were analysed: the dynamic shear viscosity $\left(\eta^{*}\right)$, the storage modulus $\left(G^{\prime}\right)$ and the loss modulus $\left(G^{\prime \prime}\right)$.

\subsection{4. $\mathrm{CO}_{2}$ uptake}

The amount of gas uptake was calculated as the percentage of weight increment of the sample due to the $\mathrm{CO}_{2}$ sorption. The initial mass was measured after drying the samples and the final weight was evaluated by weighting the samples immediately after they were removed from the pressure vessel. The time between the gas depressurization and the weight measurement was around 2 min and during this time some gas was lost due to gas diffusion out of the sample. Thus, these measurements are only an estimation of the solubility that has been only used for comparison between samples.

\subsubsection{Cellular structure}

With the aim of maintaining the cellular structure for the microscopic visualization, samples were cooled in liquid nitrogen and fractured. There were also coated with gold using a sputter coater (model SCD 005, Balzers Union). The cellular structure of the samples was analysed using an ESEM Scanning Electron Microscope (QUANTA 200 FEG). Several parameters must be measured in order to obtain a complete analysis of the cellular structure. A specific software based on ImageJ/FIJI [45] has been used for this purpose. Firstly the average cell size $(\phi)$ has been measured and the cell size distribution and the standard deviation of the cell size distribution (SD) have been obtained. The parameter $\mathrm{SD} / \phi$ was calculated as an indicator of the homogeneity of the cellular structure which is useful for comparison between micro and nanocellular materials. Cell nucleation density $\left(\mathrm{N}_{0}\right)$ has been determined using Kumar's theoretical approximation [46] according to Eq. (1) where $N_{v}$ is the cell density, $n$ is the number of cells in the image and $A$ is the area of the image. More than 200 cells of different areas of each cellular material have been used for this analysis. As the fracture surface may not be perfectly flat, some overestimation of the cell density can result from this analysis. However, fracture is the usual way of preparing samples for analysis of cell structure, so the results of this work will be comparable with those presented in previous literature.

$$
N_{0}=\frac{N_{v}}{\rho_{r}} \text { where } N_{v}=\left[\frac{n}{A}\right]^{3 / 2}
$$

In this work, bimodal cellular structures (with cells in the micro and in the nano scale) have been obtained. This type of cell size populations are characterized by a huge number of nanocells and a small number of microcells that occupy a significant volume of the 
a)

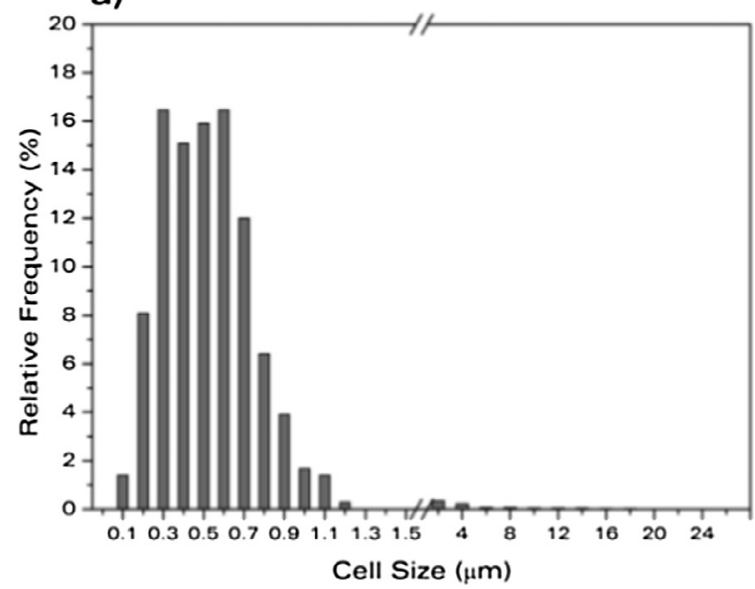

b)

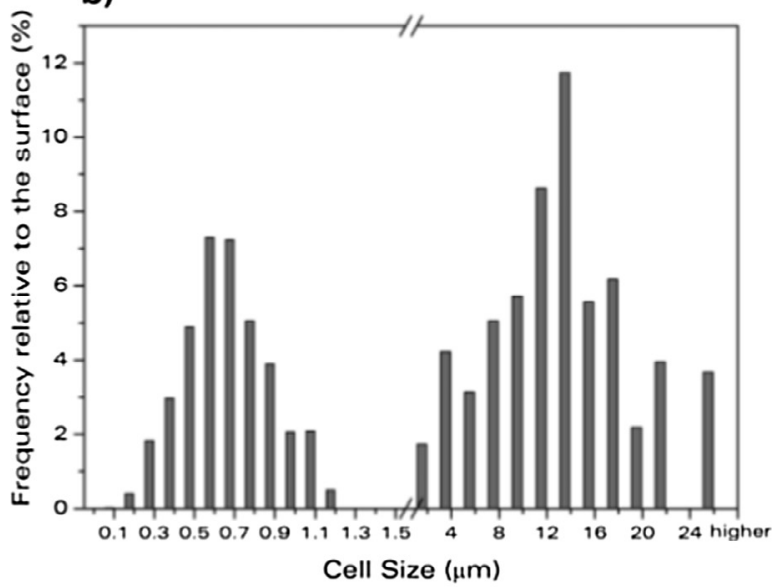

Fig. 1. Cell size distribution of a bimodal cellular structure with cells in the micro and in the nano scale (a) without the correction that takes into account the size of each cell and (b) with the correction that takes into account the size of each cell (Eq. (2)).

sample. Due to this, by using a standard cell size distribution in which the number of cells for a given size is represented the contribution of microcells would be negligible. Therefore, it is convenient to introduce a correction to the standard way of presenting cell size distributions accounting for the size of each cell.

The correction we have used consists on multiplying the number of cells of a given diameter ( $n_{\text {cells, } x}$, where $x$ is the cell diameter) times the surface of the cell (that is, times its radius square). Eq. (2) gives the formula to calculate the frequency relative to the surface for each cell size $x$ :

$$
\text { Frequency relative to the } \operatorname{surface}(x)=100 \frac{n_{\text {cells }, x} \pi\left(\frac{x}{2}\right)^{2}}{\sum_{x_{i}} n_{\text {cells }, x_{i}} \pi\left(\frac{x_{i}}{2}\right)^{2}}
$$

Fig. 1 shows an example of the cell size distribution of a bimodal structure without correction (Fig. 1a) and with the correction (Fig. 1b). In Fig. 1a the microcells play a minor role because it number is negligible. After the correction with the surface of the cell, the bimodal structure is clearly observed (Fig. 1b) and both nano and micro cells are clearly appreciated.

Furthermore, another interesting cellular structure parameter for these bimodal cellular materials is the relative volume occupied by the population of nanometric cells. This parameter has been calculated by measuring the area of these cells in the SEM images $A_{n}$ and the total area of the image, $A_{t}$, according to Eq. (3). The surface ratio should be equal to the volume ratio when representative surfaces are analysed, according to the Delesse stereology principle [47]. The fraction corresponding to the nanocellular population can be calculated from Eq. (3).

$$
\text { Volume fraction nanometric cells }(\%)=100\left(\frac{A_{n}}{A_{t}}\right)
$$

\section{Results and discussion}

\subsection{Solid nanocomposites}

\subsubsection{Solid nanocomposites morphology}

Fig. 2 shows the SEM micrographs of the solid nanocomposites with the different types and contents of sepiolites. These high magnification images show regions in which the sepiolites are well-dispersed: even individual nanoparticles can be appreciated in the images (see red circles in Fig. 2). At this magnification, particle aggregates cannot be observed. However, some micrometric particle aggregates appear too (see examples in Fig. 3). It is not possible to detect simultaneously (in the same micrograph) both individual particles and aggregates because of their very different size (nanometric vs. micrometric). Bright points in the SEM images displayed in Fig. 3 might be attributed to individual sepiolites, but it is necessary to use higher magnifications in order to see the nanoparticles as clear as in Fig. 2. Particle aggregates present a wide distribution of sizes, from a few microns to tens of microns. As the particle content increases these aggregates look larger and appear more often in the images; however, this fact cannot be showed in the images since the aggregates are small and not very numerous in any case, so it is not possible to show a collection of them in the same image. This result is expected in nanocomposites: as the particle content increases, so does the probability of interaction between particles and thus the number and size of the aggregates $[17,48]$.

The conclusion is that the extrusion process used to melt compound the nanocomposites was able to disperse up to some extent the particles, but some aggregates were still present after this process. Therefore, the production process was ineffective to fully 

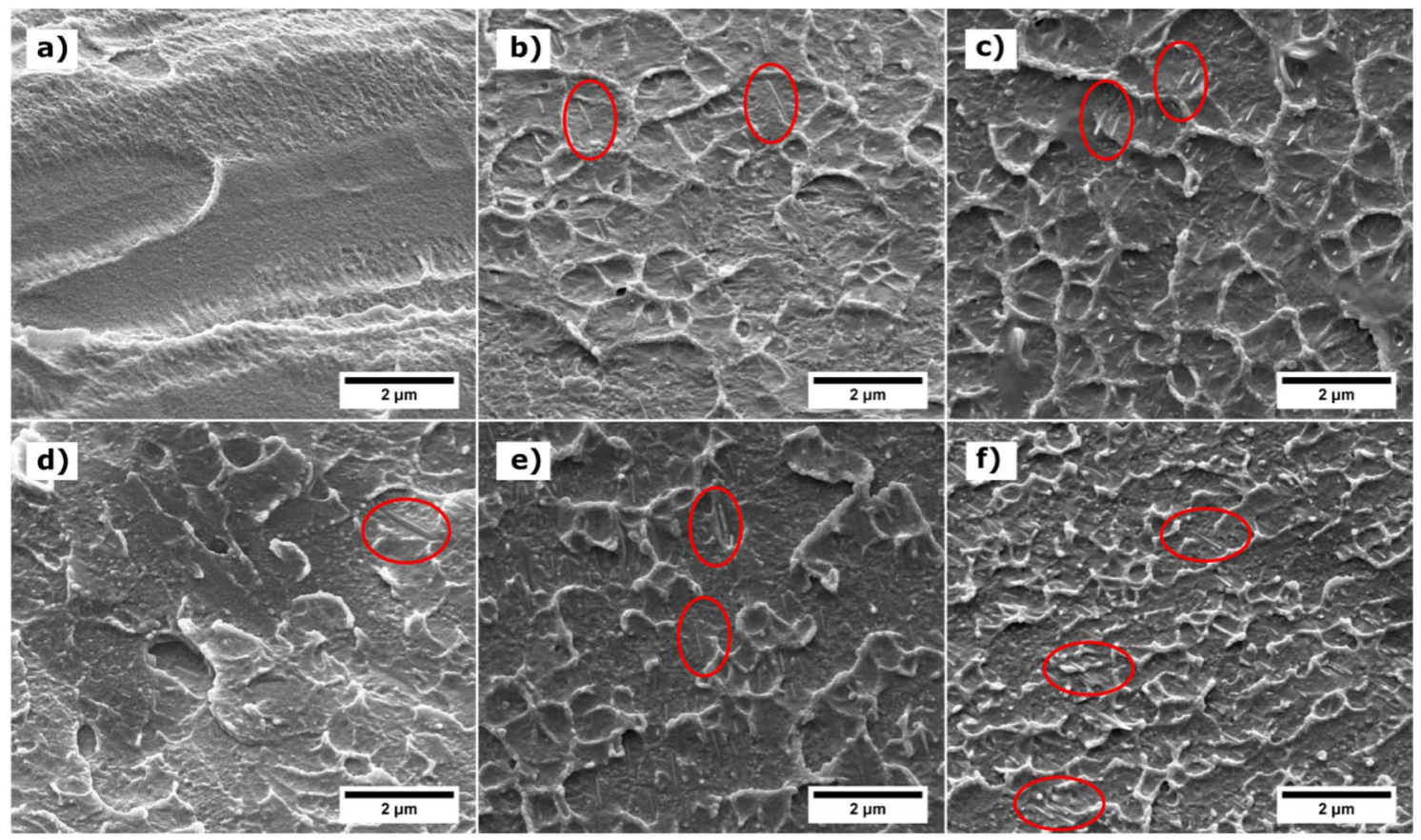

Fig. 2. High magnification SEM micrographs of the nanocomposites: (a) PMMA, (b) 0.5\%_S-N, (c) 0.5_\%S-QAS, (d) 0.5\%S-S, (e) 1_\%S-QAS and (f) 1.5 - $\%$ S-QAS.
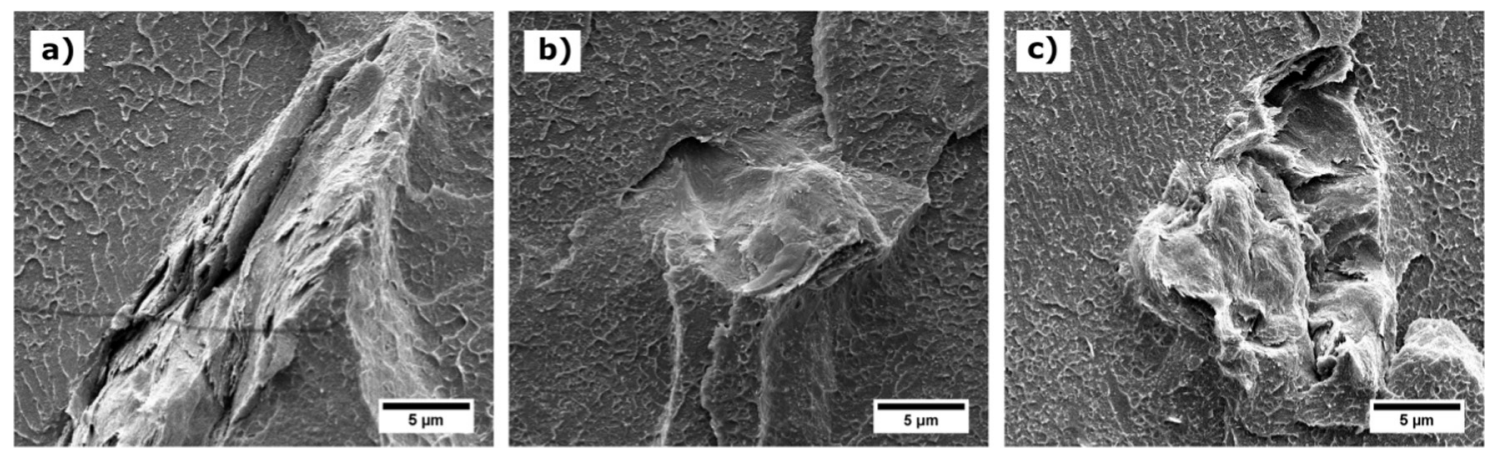

Fig. 3. SEM micrographs of the nanocomposites showing some examples of particle aggregates: (a) 0.5\%_S-QAS, (b) $1 \%$ _S-QAS and (c) $1.5 \%$ _S-QAS.

disperse the fillers in the matrix and this was independent of the surface treatment used in each type of particle. To obtain a better characterization of the dispersion state in each system the rheological behaviour was studied.

\subsubsection{Rheological behaviour}

Fig. 4a shows the complex viscosity as a function of the angular frequency for the three materials containing a fixed content $(0.5 \mathrm{wt} \%)$ of sepiolites together with that of the processed PMMA. These results show that the addition of sepiolites induces an increase in the zero-shear viscosity when compared with the reference material without sepiolites (Table 2). The blend with S-N presents the highest complex viscosity. Moreover, the crossover frequency is shifted to slightly higher angular frequencies in the three blends; although, they all present a unique crossover point (Table 2). That means that the dispersion of the particles at this content has not led to a percolation network, regardless of the type of particle employed. Besides, there are no significant variations in the slopes of $G^{\prime}$ and $G^{\prime \prime}$ at low frequencies, in the terminal region (Table 2), since they are proportional to $\omega^{2}$ and $\omega$, respectively. This is the typical polymer terminal relaxation behaviour [42]. If a percolation network had been obtained, the slopes would have tended to zero at low frequencies and also $\mathrm{G}^{\prime}$ would have been higher than $\mathrm{G}^{\prime \prime}$ in all the frequency range (characteristic behaviour of solid-like materials). The material with S-QAS shows a slightly smaller $G^{\prime}$ slope when compared with the blends with other sepiolite types. This indicates that a slightly better dispersion has been achieved in this kind of nanocomposite.

The complex viscosity of the blends containing S-QAS at different clay contents is plotted in Fig. 4b. There are not significant differences between the blends at low contents $(0.5$ and $1 \mathrm{wt} \%)$. However, the blend with $1.5 \mathrm{wt} \%$ of sepiolites S-QAS shows a higher viscosity than the others, caused by the higher particle content [42,43]. Regarding the crossover frequency, no effect is observed as the particle content increases (Table 2), but there is still only one crossover point. This shows that a percolation network has not been 


\section{a)}

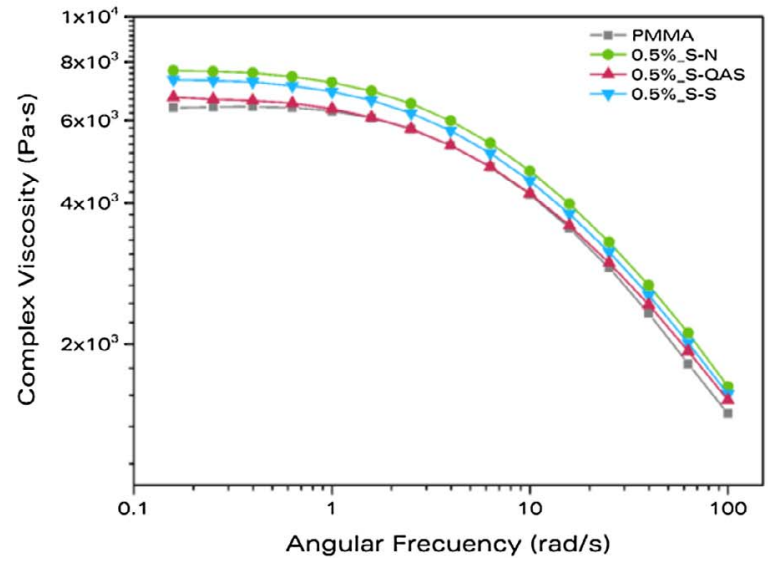

b)

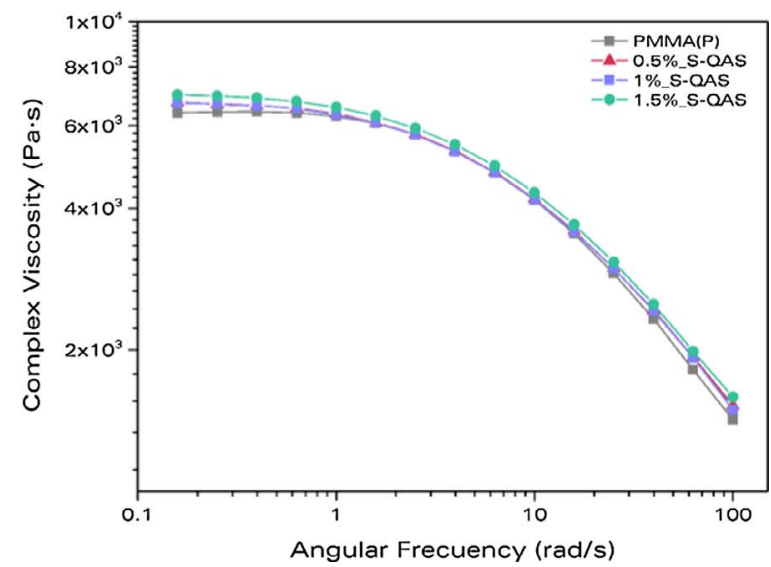

Fig. 4. Complex viscosity as a function of the frequency for the materials (a) with $0.5 \mathrm{wt} \%$ of sepiolites and (b) with different contents of S-QAS.

Table 2

Dynamic shear properties of the solid materials.

\begin{tabular}{|c|c|c|c|c|}
\hline Material & Zero shear viscosity (Pa s) & Slope G' & Slope $G^{\prime \prime}$ & Crossover frequency ( $\mathrm{rad} / \mathrm{s})$ \\
\hline PMMA & $6377 \pm 189$ & $1.78 \pm 0.07$ & $0.99 \pm 0.01$ & $51.34 \pm 1.37$ \\
\hline $0.5 \%$ S-N & $7663 \pm 83$ & $1.88 \pm 0.04$ & $1.00 \pm 0.00$ & $51.86 \pm 0.59$ \\
\hline $0.5 \%$ S-QAS & $6723 \pm 85$ & $1.70 \pm 0.12$ & $0.98 \pm 0.01$ & $57.64 \pm 2.28$ \\
\hline $0.5 \%$ S-S & $7327 \pm 74$ & $1.87 \pm 0.04$ & $0.99 \pm 0.00$ & $52.42 \pm 0.25$ \\
\hline $1 \%$ S-QAS & $6700 \pm \pm 21$ & $1.58 \pm 0.06$ & $0.99 \pm 0.01$ & $56.97 \pm 0.90$ \\
\hline $1.5 \%$ S-QAS & $6970 \pm 1$ & $1.69 \pm 0.06$ & $0.99 \pm 0.01$ & $57.10 \pm 1.05$ \\
\hline
\end{tabular}

achieved for the particle contents used in this paper. In addition, the slopes of $G^{\prime}$ and $G^{\prime \prime}$ are neither affected by the particle content (Table 2). Therefore, for this type of particles the percolation network should be found by increasing the particle content over $1.5 \mathrm{wt}$ $\%$.

The main conclusion of the analysis of the dynamic shear properties is that there are no great differences between the pure PMMA and the blends with sepiolites. Only a slight increase in the complex viscosity has been found as a consequence of the particle addition, but the rheological behaviour of the polymer is not strongly modified by the addition of sepiolites at least for the particle contents studied. Besides, it is not possible to achieve a percolated network neither by changing the particle type nor by increasing the particle content up to $1.5 \mathrm{wt} \%$. This fact indicates that some particles could be forming aggregates with a large size (in the micrometric range). These results match with those obtained after the observation of the nanocomposites morphology by SEM. On the one hand some aggregates, with a micrometric size, were detected and on the other hand, SEM micrographs indicate that particles are not forming a random pathway throughout the systems, which once again indicates that a percolated network has not been obtained with this kind of systems. In addition, the difference in dispersion between the three type of particles analysed is small, the particle S-QAS being slightly better dispersed.

\subsection{Cellular nanocomposites}

\subsubsection{Effect of the saturation pressure}

3.2.1.1. Effect of the particle type. Table 3 shows the amount of gas absorbed by the blends with $0.5 \mathrm{wt} \%$ of sepiolites at the three different saturation pressures used: 10, 20 and $30 \mathrm{MPa}$. As expected, these data show that the amount of gas uptake increases with pressure, from around $25 \mathrm{wt} \%$ uptake at $10 \mathrm{MPa}$ to more than a $30 \mathrm{wt} \%$ at $30 \mathrm{MPa}$. With these amounts of gas uptake of 25,28 and $30 \mathrm{wt} \%$ and according to Ref. [15] glass transition temperature of the polymer matrix is depressed up to around $10{ }^{\circ} \mathrm{C}, 0{ }^{\circ} \mathrm{C}$ and $-5{ }^{\circ} \mathrm{C}$, respectively The nanocomposites containing a $0.5 \mathrm{wt} \%$ of sepiolites present a slightly lower solubility than the pure polymer for the three pressures under study. Assuming that there is no gas sorption in the particles, the solubility values can be corrected to the gas absorbed by the polymer (Table 3, gas uptake corrected $(\mathrm{c} *)$ ). These corrected values recover the solubility of the pure polymer, showing that indeed the reduction in solubility is due to the presence of the particles, which do not promote a higher $\mathrm{CO}_{2}$ uptake under these conditions.

The relative density of the cellular samples as a function of the saturation pressure is shown in Fig. 5. Relative densities between 0.24 and 0.3 have been obtained for all the materials produced (Table 3). It is observed that an increase in the saturation pressure leads to a small reduction in the relative density. This trend is a consequence of the plasticization effect of the $\mathrm{CO}_{2}$ : when the gas diffuses into a polymer, the glass transition temperature drops [49-52], and the polymer is now characterized by its effective glass

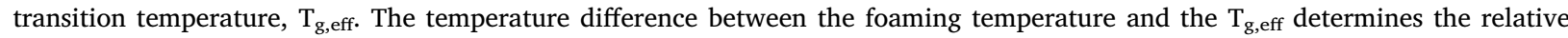


Table 3

Gas uptake, and cellular structure characteristics of the cellular samples produced with the blends containing $0.5 \mathrm{wt} \%$ of sepiolites.

\begin{tabular}{|c|c|c|c|c|c|c|c|c|c|}
\hline Sample & $\begin{array}{l}\text { Saturation } \\
\text { Pressure (MPa) }\end{array}$ & $\begin{array}{l}\text { Gas uptake } \\
(\mathrm{wt} \%)\end{array}$ & $\begin{array}{l}\text { Gas uptake } \\
\mathrm{c}^{*}(\mathrm{wt} \%)\end{array}$ & Relative Density & $\begin{array}{l}\text { Cell Nucleation Density } \\
\left(\text { nuclei/ } / \mathrm{cm}^{3} \text { ) }\right.\end{array}$ & $\begin{array}{l}\text { Cell Size } \\
1(\mathrm{~nm})\end{array}$ & $\mathrm{SD}_{1} / \phi_{1}$ & $\begin{array}{l}\text { Cell Size } \\
2(\mu \mathrm{m})\end{array}$ & $\mathrm{SD}_{2} / \phi_{2}$ \\
\hline PMMA & 10 & 24.6 & - & $0.29 \pm 0.01$ & $(5.8 \pm 0.2) \cdot 10^{11}$ & 1644 & 0.89 & - & - \\
\hline $0.5 \% \_S-N$ & 10 & 24.3 & 24.4 & $0.29 \pm 0.01$ & $(9.9 \pm 2.3) \cdot 10^{11}$ & 1471 & 0.73 & - & - \\
\hline $\begin{array}{r}0.5 \% \text { S- } \\
\text { QAS }\end{array}$ & 10 & 24.4 & 24.5 & $0.27 \pm 0.01$ & $(1.6 \pm 0.2) \cdot 10^{13}$ & 470 & 0.48 & 6.5 & 0.77 \\
\hline $0.5 \% \_S-S$ & 10 & 24.4 & 24.5 & $0.29 \pm 0.01$ & $(4.8 \pm 0.3) \cdot 10^{11}$ & 1868 & 0.77 & - & - \\
\hline PMMA & 20 & 27.4 & - & $0.26 \pm 0.01$ & $(1.48 \pm 0.02) \cdot 10^{12}$ & 1396 & 0.62 & - & - \\
\hline 0.5\%_S-N & 20 & 27.2 & 27.3 & $0.29 \pm 0.01$ & $(1.42 \pm 0.01) \cdot 10^{12}$ & 1454 & 0.50 & - & - \\
\hline $\begin{array}{r}0.5 \% \_S- \\
\text { QAS }\end{array}$ & 20 & 27.3 & 27.4 & $0.24 \pm 0.01$ & $(1.7 \pm 0.2) \cdot 10^{13}$ & 494 & 0.53 & 6.8 & 0.91 \\
\hline $0.5 \% \_S-S$ & 20 & 27.3 & 27.4 & $0.24 \pm 0.01$ & $(1.4 \pm 0.4) \cdot 10^{12}$ & 1353 & 0.83 & - & - \\
\hline PMMA & 30 & 30.2 & - & $0.24 \pm 0.01$ & $(1.9 \pm 0.2) \cdot 10^{14}$ & 286 & 0.59 & - & - \\
\hline $0.5 \% \_S-N$ & 30 & 29.8 & 29.9 & $0.25 \pm 0.01$ & $(1.8 \pm 0.1) \cdot 10^{14}$ & 303 & 0.50 & - & - \\
\hline $\begin{array}{r}0.5 \% \_S- \\
\text { QAS }\end{array}$ & 30 & 29.9 & 30.1 & $0.23 \pm 0.01$ & $(2.2 \pm 0.7) \cdot 10^{13}$ & 447 & 0.72 & 8.5 & 0.74 \\
\hline $0.5 \% \_S-S$ & 30 & 29.8 & 29.9 & $0.26 \pm 0.01$ & $(3.5 \pm 0.6) \cdot 10^{14}$ & 230 & 0.57 & - & - \\
\hline
\end{tabular}

$c^{*}$ : corrected by the amount of sepiolites.

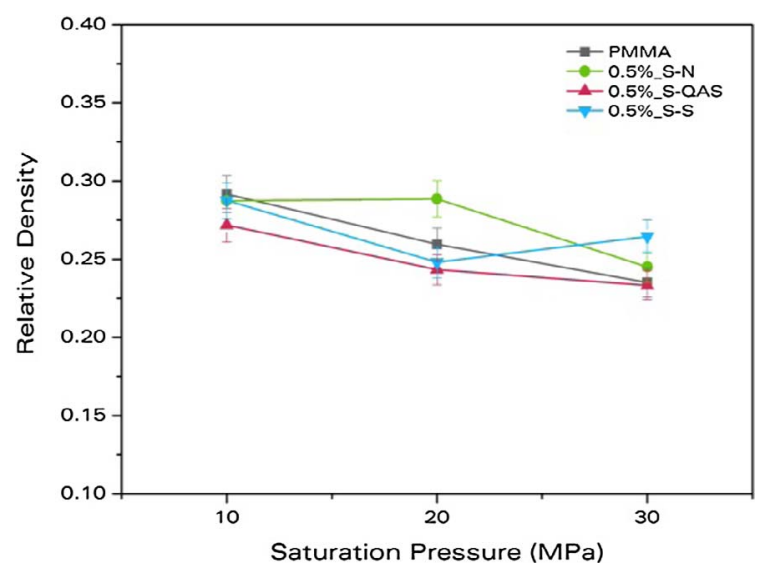

Fig. 5. Relative density as a function of the saturation pressure for the blends containing $0.5 \mathrm{wt} \%$ of sepiolites and for the pure PMMA. Foaming conditions were $80{ }^{\circ} \mathrm{C}$ and $2 \mathrm{~min}$.

density obtained, because once the $\mathrm{T}_{\mathrm{g} \text {,eff }}$ reaches the temperature of the thermal bath the polymer is no longer in the rubbery state and has no mobility to grow. At a higher pressure, the $\mathrm{T}_{\mathrm{g} \text {,eff }}$ of the polymer is smaller because of the plasticization effect of a higher amount of $\mathrm{CO}_{2}$. Therefore, after the saturation at three different pressures, three different initial states (characterized by three different $\mathrm{T}_{\mathrm{g} \text {,eff }}$ ) are obtained. The $\mathrm{T}_{\mathrm{g} \text {,eff }}$ of the materials saturated at $10 \mathrm{MPa}$ is the highest, whereas the $\mathrm{T}_{\mathrm{g} \text {,eff }}$ of the materials saturated at $30 \mathrm{MPa}$ is the lowest. The foaming temperature is the same, so the temperature difference between the foaming temperature and the $\mathrm{T}_{\mathrm{g} \text {,eff }}$ is higher for the materials saturated at $30 \mathrm{MPa}$; consequently, these materials have more time to grow until they reach the thermal bath temperature. In short, a higher difference between the foaming temperature and the $\mathrm{T}_{\mathrm{g} \text {,eff }}$ produces a smaller final density (more time to grow). Besides, at higher pressures there is more gas dissolved in the polymer available for growing. These two phenomena explain the reduction in density observed when increasing saturation pressure in these experiments (Fig. 5).

On the other hand, there are no significant differences between the relative density of the neat polymer PMMA and that of the materials with sepiolites. The gas uptake was the same, thus at this content sepiolites do not affect the ability to expand of the PMMA, independently of the particle surface modification. These results match with the similar zero-shear viscosities observed.

Cellular structure of the samples produced at $10 \mathrm{MPa}$ is shown in Fig. 6 as an example. For this saturation pressure, two different structures can be detected. On the one hand, the pure polymer (Fig. 6a) and the blends with S-N (Fig. 6c) and S-S (Fig. 6d) show a microcellular structure, with cell sizes of the order of $1.6 \mu \mathrm{m}$ (Table 3). The three systems show a similar cell size distribution (Fig. 6 , second column). However, in the blend containing $0.5 \mathrm{wt} \%$ of S-QAS there is a bimodal distribution of the cell size (Fig. $6 \mathrm{c}$ ). At low magnification, a microcellular population of cells is detected, but at high magnification (see zoomed square in Fig. 6c) a nanocellular structure is observed among the microcellular pores. This results in a bimodal distribution of the cell size. The cell size distribution of this system, represented using the same criteria that the others (Fig. 6c, second column), does not show this bimodality due to the very different cell sizes. Thus, the corrected cell size distributions diagrams have been plotted too (squared graphs). Comparing these corrected distributions it is clearly seen that only the material containing S-QAS shows a clear bimodal distribution of the cell size. Notice the break in the cell size axis in this corrected graph after 1.5 micrometres and the change of scale after the break. Due to this 

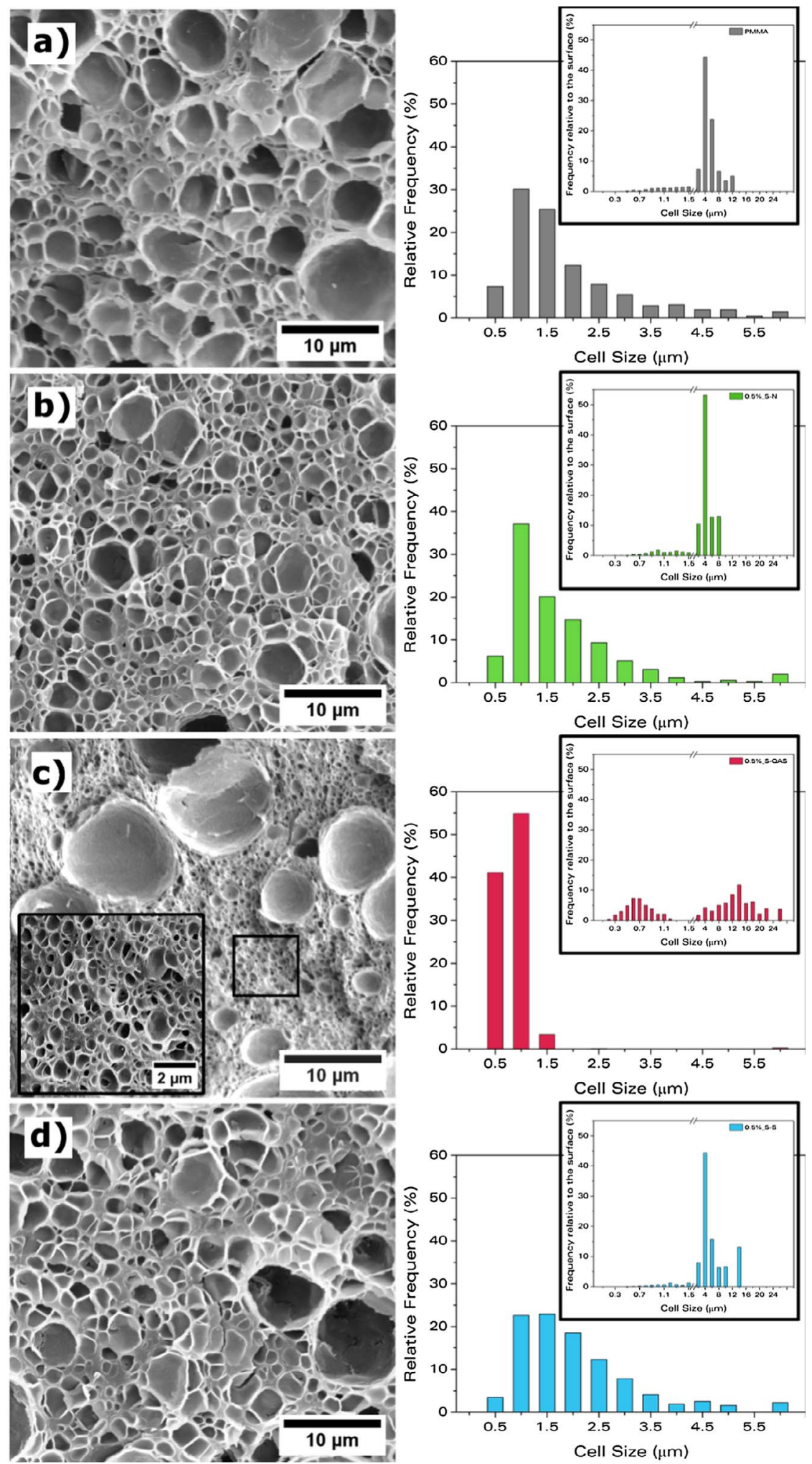

Fig. 6. SEM images and cell size distributions of the cellular samples produced at $10 \mathrm{MPa}$ of saturation pressure and $80^{\circ} \mathrm{C}$ of foaming temperature. (a) PMMA, (b) $0.5 \%$ S-N, (c) 0.5\%_S-QAS and (d) 0.5\%_S-S. The squared graphs correspond to the cell size distributions calculated using the correction (Eq. (2)). 
Table 4

Characteristics of the bimodal cellular structure of the cellular materials based of $0.5 \%$ S-QAS for the three saturation pressures used in this work.

\begin{tabular}{|c|c|c|c|c|c|c|}
\hline \multirow[b]{2}{*}{ Saturation pressure (MPa) } & \multicolumn{3}{|l|}{ Main population } & \multicolumn{3}{|c|}{ Secondary population } \\
\hline & $\begin{array}{l}\text { Volume fraction } \\
(\%)\end{array}$ & $\begin{array}{l}\text { Cell size } \phi \\
(\mathrm{nm})\end{array}$ & $\begin{array}{l}\text { Standard deviation } S D \\
(\mathrm{~nm})\end{array}$ & $\begin{array}{l}\text { Volume fraction } \\
(\%)\end{array}$ & $\begin{array}{l}\text { Cell size } \phi \\
(\mu \mathrm{m})\end{array}$ & $\begin{array}{l}\text { Standard deviation } S D \\
(\mu \mathrm{m})\end{array}$ \\
\hline 10 & 56.5 & 470 & 227 & 43.5 & 6.5 & 5.0 \\
\hline 20 & 56.1 & 494 & 262 & 43.9 & 6.8 & 6.2 \\
\hline 30 & 61.5 & 447 & 321 & 38.5 & 8.5 & 6.3 \\
\hline
\end{tabular}

difference in size between the largest and the smallest cells, we have separate both contributions in two populations of cells: main (nanocellular) and secondary (microcellular) structures. The cell size corresponding to the nanocellular population has been denoted as $\phi_{1}$ (main structure) and the microcellular cell size has been denoted as $\phi_{2}$ (secondary structure) in Table 3 . The microcellular population is very heterogeneous, with cell sizes ranging from a few microns to tens of microns, the nanocellular population being more homogeneous (check the parameters $\mathrm{SD}_{\mathrm{i}} / \phi_{i}$, with $\mathrm{i}=1$ and 2 , in Table 3 ). This kind of structure has been found in all the samples containing S-QAS, regardless the saturation pressure used. This bimodal distribution has been previously reported in PS foams with sepiolites [35] and can be caused by particle aggregates. From the shear rheology measurements and the SEM images it was concluded that the dispersion of the particles was not enough to achieve a percolation network and that particles were forming aggregates. This could be the reason of the appearance of the microcellular population. The individual nanometric sepiolites would act as nucleating sites for nanocellular pores and micrometric aggregates could become preferable nucleation places for larger pores. Besides, as observed in the SEM micrographs, there was a wide distribution of the aggregates sizes, which could be leading a wide distribution of the cell sizes in the microcellular population. However, further research is needed to fully understand the origin of these bimodal distributions.

The effect of the saturation pressure in the bimodal cellular structure observed for the material $0.5 \%$ S-QAS is shown in Table 4 and Fig. 7. For the three pressures under study, the fraction of nanometric cells is larger than that of micrometric cells (Table 4), justifying the consideration of the nanometric cells as the main population of cells. Besides, volume fractions larger than $50 \%$ of nanometric cells have been obtained regardless the saturation pressure. Similar volume fractions are observed at 10 and $20 \mathrm{MPa}$, whereas at $30 \mathrm{MPa}$ the volume occupied by the nanometric cells is slightly higher (Table 4).

Regarding the cell size distributions, it is observed that the two distributions, main and secondary populations of cells, are wider as saturation pressure increases (Fig. 7). Meanwhile similar cell sizes are found at 10 and $20 \mathrm{MPa}$, increasing the saturation pressure up to $30 \mathrm{MPa}$ seems to result also in smaller nanometric cells and slightly larger micrometric cells (Table 4).

The evolution of the cell nucleation density and the cell size with the saturation pressure for the pure polymer and the nanocomposites with $0.5 \mathrm{wt} \%$ of sepiolites is shown in Fig. 8 and Table 3 . The cell size represented in Fig. $8 \mathrm{~b}$ is that of the nanometric pores.

Two different behaviours can be appreciated for the cell nucleation density (Fig. 8a). On the one hand, cell nucleation density of PMMA increases as saturation pressure increases. This is predicted by classical nucleation theory and it is the expected behaviour for pure homopolymers (homogeneous nucleation): higher pressures lead to higher solubilities, which turn into higher nucleation densities and smaller cell sizes [20]. The same trend is observed for 0.5\%_S-N and 0.5\%_S-S: nucleation increases with pressure. Besides, the values of cell nucleation densities are similar for these three materials; these values vary between $10^{11}$ nuclei $/ \mathrm{cm}^{3}$ at $10 \mathrm{MPa}$ and $10^{14}$ nuclei $/ \mathrm{cm}^{3}$ at $30 \mathrm{MPa}$. Therefore, these two types of particles, S-N and S-S, at a content of $0.5 \mathrm{wt} \%$, do not produce any nucleation effect in PMMA, as the nucleation observed is the same as the one of the pure polymer. On the other hand, the blend produced with the sepiolite modified with a quaternary ammonium salt, $0.5 \%$ _S-QAS, shows a completely different behaviour. Cell nucleation density only varies from $1.6 \cdot 10^{13}$ nuclei $/ \mathrm{cm}^{3}$ at $10 \mathrm{MPa}$ to $2.2 \cdot 10^{13}$ nuclei $/ \mathrm{cm}^{3}$ at $30 \mathrm{MPa}$, that is, cell nucleation density is almost constant regardless the saturation pressure employed. This is an indicator that nucleation is no longer purely homogeneous when these sepiolites are added. Besides, at $20 \mathrm{MPa}$ nucleation is 11 times higher than that of the neat PMMA, and this factor is increased up to 28 times at $10 \mathrm{MPa}$. Therefore a $0.5 \mathrm{wt} \%$ of S-QAS produces a clear nucleation effect in PMMA, whereas the

a)

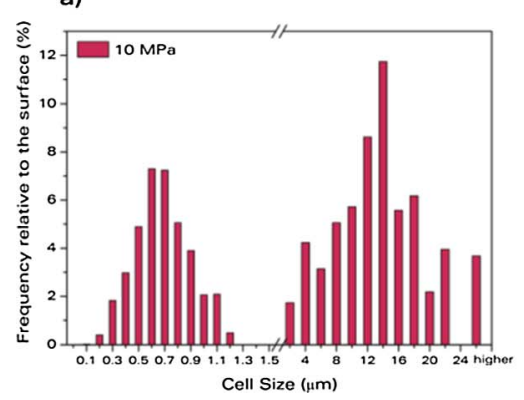

b)

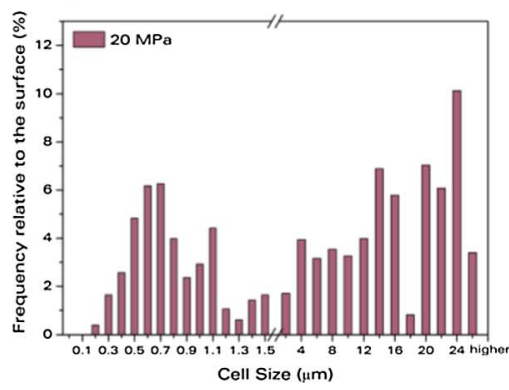

c)

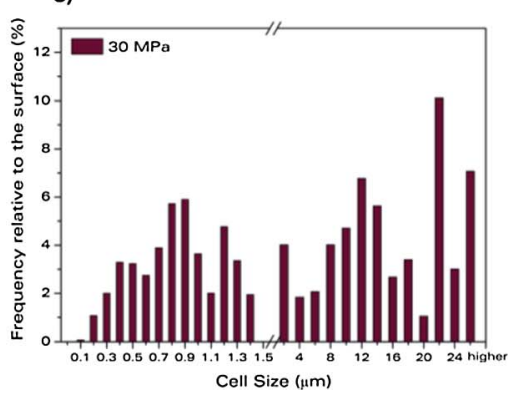

Fig. 7. Cell size distributions of the cellular materials based on $0.5 \%$ S-QAS at different saturation pressures: (a) $10 \mathrm{MPa}$, (b) $20 \mathrm{MPa}$ and (c) $30 \mathrm{MPa}$. 
a)

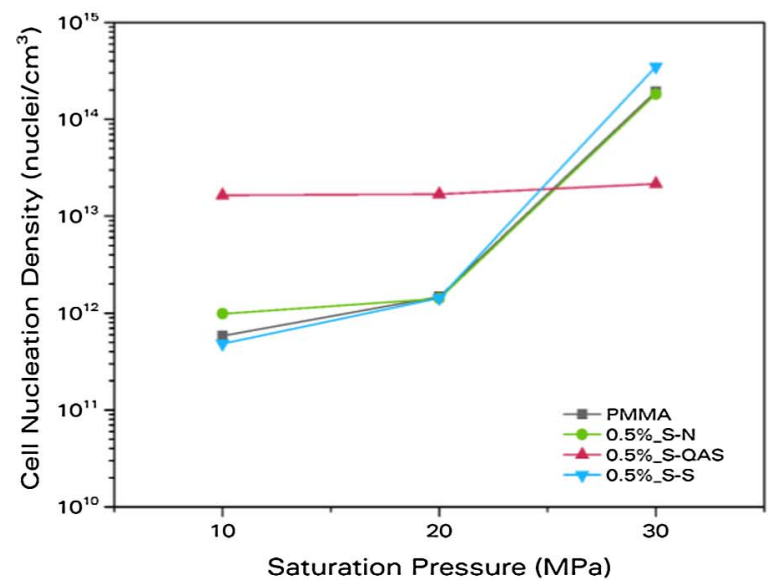

b)

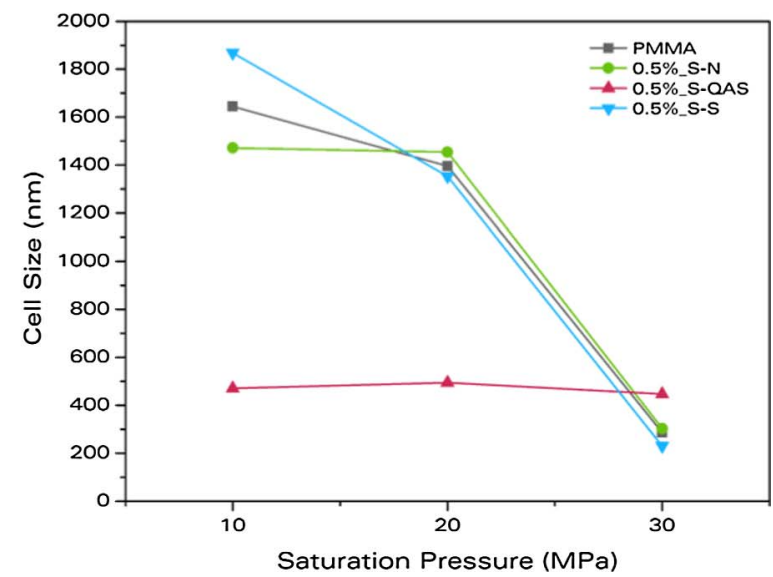

Fig. 8. (a) Cell nucleation density and (b) cell size as a function of the saturation pressure for the blends containing 0.5 wt $\%$ of sepiolites and the pure PMMA.

rest of the particles do not have any affect. From the rheological results it was concluded that a slightly better dispersion was obtained with the sepiolite S-QAS, but the difference between the three types of particles was small and isolated sepiolites were found in the three solid nanocomposites. Therefore, a possible explanation of the nucleating effect of the sepiolite S-QAS should take into account the interaction between the particle, the polymer and the $\mathrm{CO}_{2}$, the surface modification of S-QAS being likely to improve its characteristics to act as a nucleating agent. In fact, some works have reported that nanoparticles with different surface treatments can be just as well dispersed but provide different nucleation efficiencies as a consequence of the interaction of the surface with the $\mathrm{CO}_{2}$ $[53,54]$. These works have shown that surface modifications with $\mathrm{CO}_{2}$ philic surfactants reduce the energy barrier for nucleus formation and allow reaching higher nucleation ratios. Thus, we believe that the commercial ammonium salt used in this work contains groups with high $\mathrm{CO}_{2}$ affinity, and then sepiolite S-QAS act as an efficient nucleating agent.

At high pressures homogeneous nucleation in the pure polymer is larger than that caused by heterogeneous nucleation in S-QAS as a consequence of the high amount of gas uptake. This result proves the complexity of producing nanocellular materials using homopolymers pointed out in the introduction: high pressures are needed, whereas the use of particles allows working at not so extreme processing conditions.

Regarding cell size, PMMA and the materials with $0.5 \mathrm{wt} \%$ of S-N and S-S present similar behaviours (Fig. 8b). The values obtained change from the microcellular range with pores larger than $1 \mu \mathrm{m}$ at $10 \mathrm{MPa}$ to the nanocellular scale with cell sizes below $300 \mathrm{~nm}$ at $30 \mathrm{MPa}$. However, as with cell density, the material with S-QAS shows a different behaviour, with nanometric pores with almost constant pore sizes along the different saturation pressures. At $10 \mathrm{MPa}$, the addition of only $0.5 \mathrm{wt} \%$ of S-QAS reduces the cell size in a factor of 3.4, from $1.6 \mu \mathrm{m}$ (in the pure PMMA, to $470 \mathrm{~nm}$ (Table 3). With respect to the secondary microcellular population found in the samples with S-QAS, cell size seems to increase with the saturation pressure (Table 3) although this secondary population of micrometric cells is very heterogeneous.

The main conclusion of this section is that among the three types of sepiolites employed in this work, only those modified with a

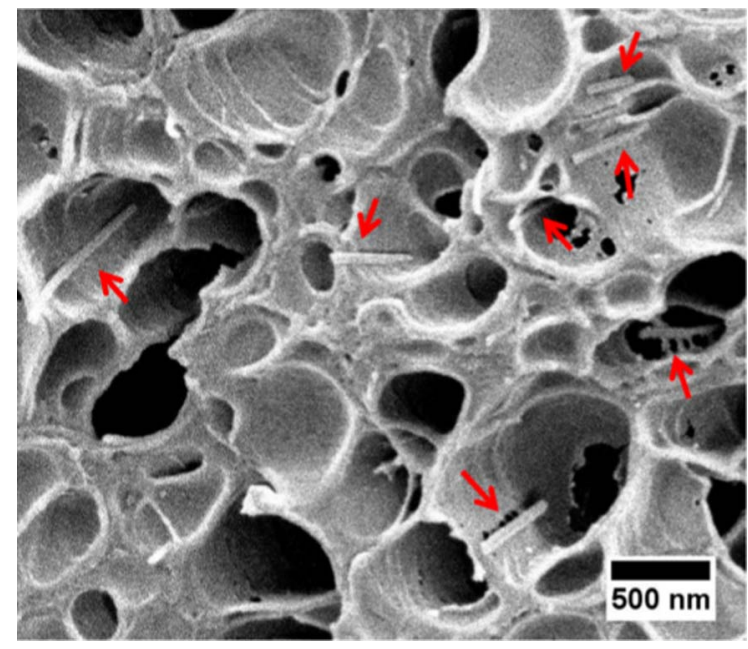

Fig. 9. High magnification micrograph showing the individual sepiolites in the surface of the nanometric cells. 
Table 5

Cellular structure characteristics of the cellular samples produced with the blends containing sepiolite S-QAS at different contents.

\begin{tabular}{|c|c|c|c|c|c|c|c|c|c|}
\hline Sample & $\begin{array}{l}\text { Saturation } \\
\text { pressure (MPa) }\end{array}$ & $\begin{array}{l}\text { Gas uptake } \\
(\mathrm{wt} \%)\end{array}$ & $\begin{array}{l}\text { Gas uptake } c^{a} \\
(\mathrm{wt} \%)\end{array}$ & Relative density & $\begin{array}{l}\text { Cell nucleation density } \\
\left(\text { nuclei } / \mathrm{cm}^{3} \text { ) }\right.\end{array}$ & $\begin{array}{l}\text { Cell size } \\
1(\mathrm{~nm})\end{array}$ & $\mathrm{SD}_{1} / \phi_{1}$ & $\begin{array}{l}\text { Cell size } \\
2(\mu \mathrm{m})\end{array}$ & $\mathrm{SD}_{2} / \phi_{2}$ \\
\hline $1 \%$ S-QAS & 10 & 24.1 & 24.3 & $0.27 \pm 0.01$ & $(3.2 \pm 2.6) \cdot 10^{13}$ & 395 & 0.57 & 4.7 & 0.72 \\
\hline $\begin{array}{r}1.5 \% \text { S- } \\
\text { QAS }\end{array}$ & 10 & 24.1 & 24.5 & $0.27 \pm 0.01$ & $(9.3 \pm 0.2) \cdot 10^{13}$ & 314 & 0.55 & 7.8 & 0.95 \\
\hline $1 \%$ S-QAS & 20 & 27.1 & 27.4 & $0.25 \pm 0.01$ & $(2.8 \pm 0.8) \cdot 10^{13}$ & 441 & 0.62 & 5.2 & 0.66 \\
\hline $\begin{array}{l}1.5 \% \text { S- } \\
\text { QAS }\end{array}$ & 20 & 27.0 & 27.4 & $0.24 \pm 0.01$ & $(9.3 \pm 0.8) \cdot 10^{14}$ & 322 & 0.50 & 5.2 & 1.29 \\
\hline $1 \%$ S-QAS & 30 & 29.8 & 30.1 & $0.25 \pm 0.01$ & $(9.0 \pm 0.4) \cdot 10^{13}$ & 308 & 0.60 & 6.2 & 0.75 \\
\hline $\begin{array}{l}1.5 \% \text { _S- } \\
\text { QAS }\end{array}$ & 30 & 29.7 & 30.2 & $0.29 \pm 0.01$ & $(9.1 \pm 0.4) \cdot 10^{13}$ & 301 & 0.64 & 6.7 & 1.08 \\
\hline
\end{tabular}

a c: corrected by the amount of sepiolites.

quaternary ammonium salt, S-QAS, have a nucleating effect in PMMA. Using particle contents as low as $0.5 \mathrm{wt} \%$ it is possible to produce materials with a bimodal cellular structure in which there is a large population of cells with sized below $500 \mathrm{~nm}$. To support our claim of nucleation in the well-dispersed sepiolites, Fig. 9 shows a high magnification SEM image of one the materials produced with S-QAS. In this image individual sepiolites (red arrows) are observed within the nanometric pores.

3.2.1.2. Effect of the particle content. The amount of gas uptake by the blends with a $1 \mathrm{wt} \%$ and a $1.5 \mathrm{wt} \%$ of S-QAS at the different saturation pressures can be found in Table 5. Solubility increases with pressure as found in the previous results. The nanocomposites containing sepiolites present a lower solubility than the pure polymer for the three pressures under study, and lower than that of the blend with $0.5 \mathrm{wt} \%$ of S-QAS. As assumed before, if no gas sorption is considered in the particles, the solubility values can be corrected to the gas absorbed by the polymer, and these corrected values recover the solubility of the pure polymer (Table 5). Therefore the assumption was again correct, and the observed reduction in solubility is due to the presence of the particles, which do not absorb $\mathrm{CO}_{2}$ under these conditions.

Relative density of the cellular samples as a function of the saturation pressure is shown in Fig. 10. An increase in the saturation pressure leads to a small reduction in the relative density (Fig. 10) for all the materials except for the one containing $1.5 \mathrm{wt} \%$ of SQAS, for which relative density seems to increase at $30 \mathrm{MPa}$. Anyway, similar relative densities, between 0.24 and 0.3 , have been obtained for all the materials (Table 5).

As it was previously commented, one interesting feature of the cellular materials produced with S-QAS is that they present a bimodal distribution of cell sizes. Fig. 11a-c shows low magnification micrographs of the three materials with different contents of SQAS produced at $10 \mathrm{MPa}$, showing the micro and the nanocellular populations. Fig. 11d-f shows high magnification micrographs that allow the visualization of the nanocellular structure found among the microcellular pores. This kind of structure has been found in all the bulk cellular materials containing S-QAS regardless the particle content and the saturation and foaming conditions (Table 5).

Fig. $11 \mathrm{~g}-\mathrm{i}$ shows the cell size distributions of these systems and Table 6 summarizes their main characteristics (volume fractions and average cell sizes). Regarding the nanocellular population, similar distributions are found at for particle contents of $0.5 \mathrm{wt} \%$ and $1 \mathrm{wt} \%$ (Fig. 11g,h), whereas for a content of $1.5 \mathrm{wt} \%$ this distribution moves to smaller cell sizes (Fig. 11i). Moreover, the weight of this distribution is higher (higher frequencies), which matches with the highest volume fraction of nanocellular cells found in this system (Table 6), almost a $80 \%$ of the volume is occupied by nanometric cells. We can then conclude that the addition of sepiolites increases the volume fraction of the main population, whereas it decreases its cell size. On the other hand, the cell size of the secondary population, which is very heterogeneous, is not significantly affected by the sepiolite content.

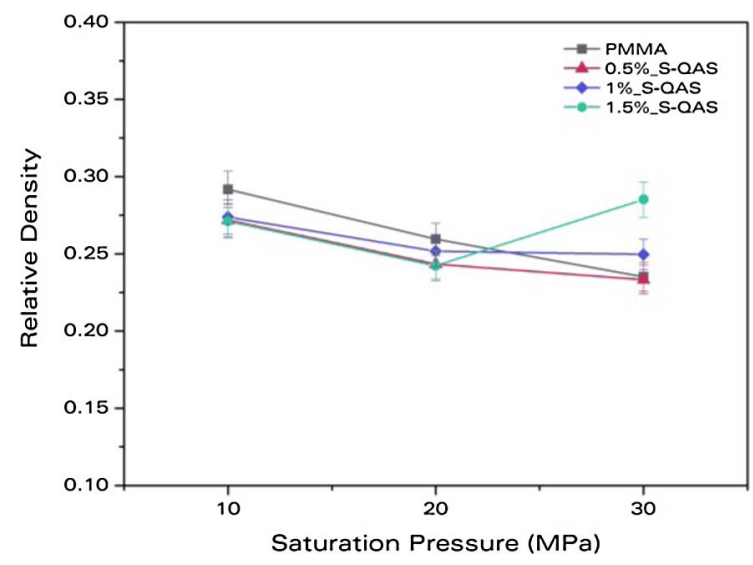

Fig. 10. Relative density as a function of the saturation pressure for the blends containing sepiolite S-QAS and the pure PMMA. 
$0.5 w t \%$
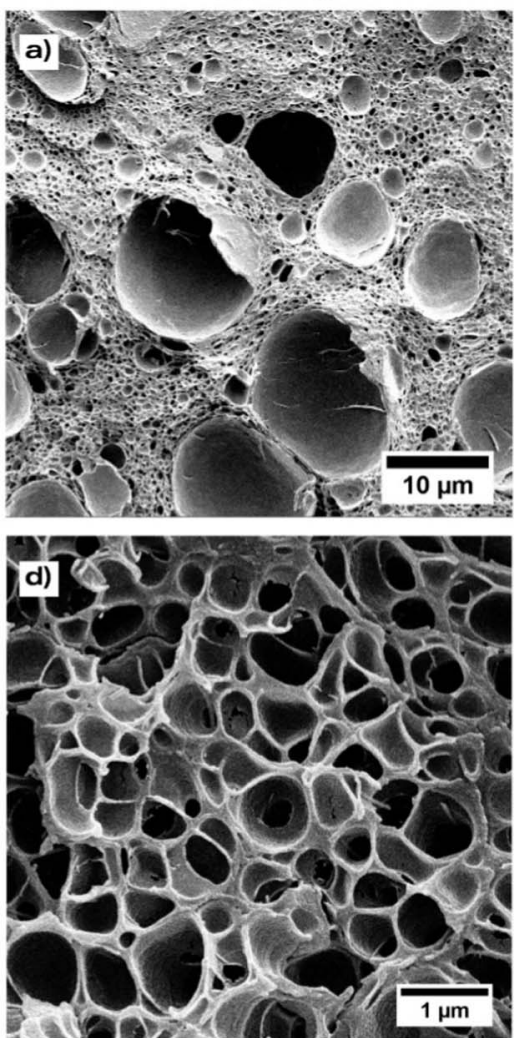

g)

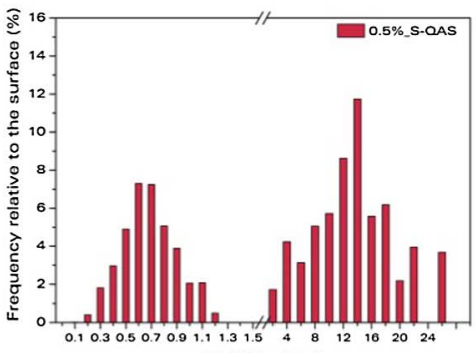

Cell Size $(\mu \mathrm{m})$
$1 \mathrm{wt} \%$
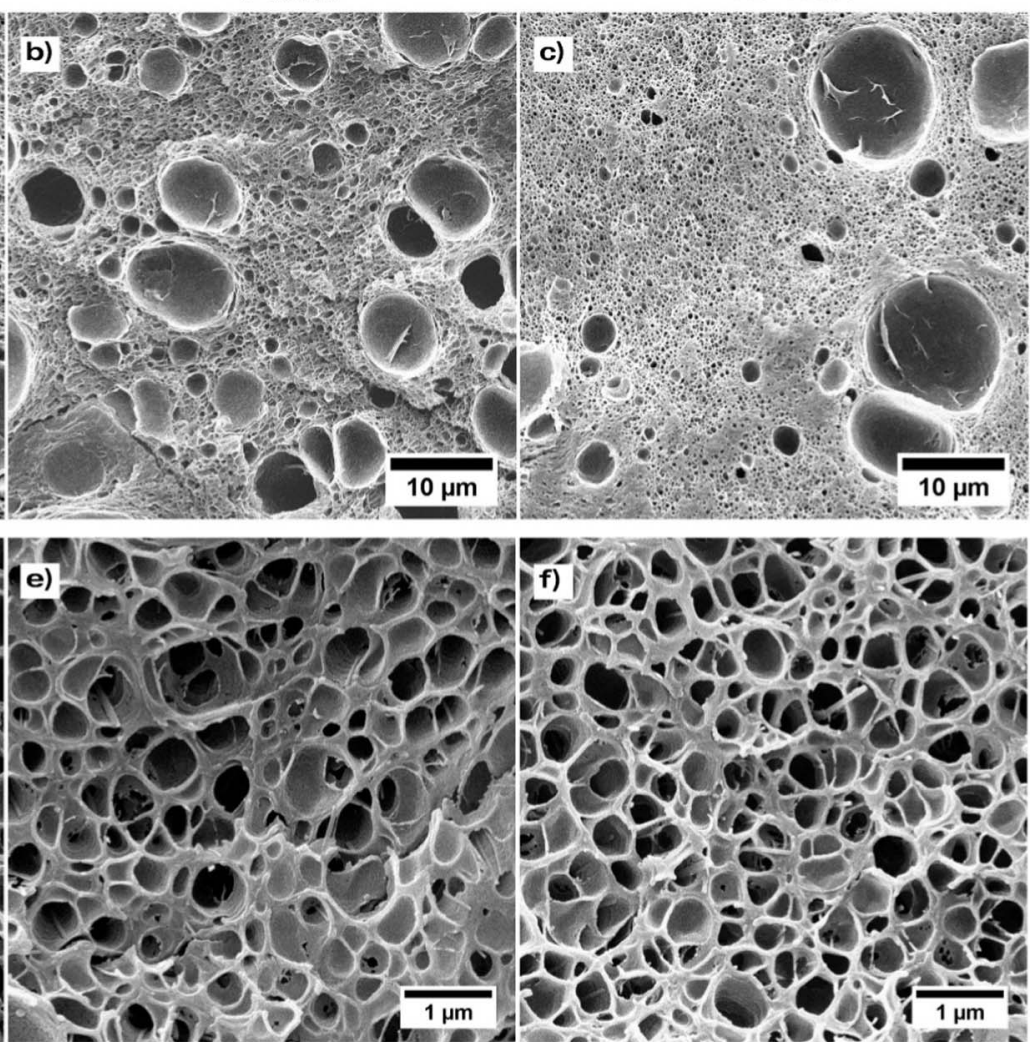

h)

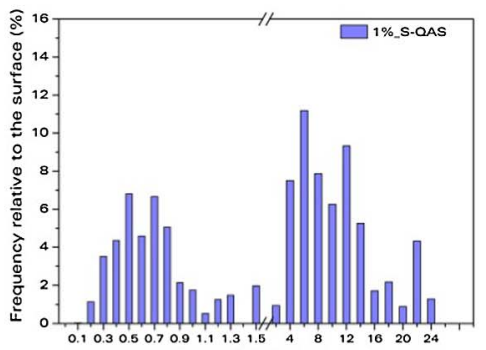

Cell Size (um) i)

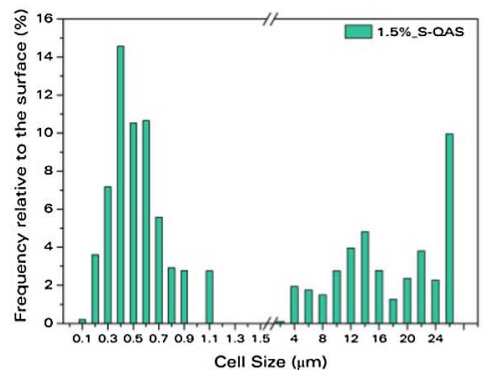

Fig. 11. SEM images of the cellular samples produced at $10 \mathrm{MPa}$ of saturation pressure and $80{ }^{\circ} \mathrm{C}$ of foaming temperature: (a) and (d) 0.5 - $\% \mathrm{~S}-\mathrm{QAS}$; (b) and (e) $11_{-} \% \mathrm{~S}$ QAS; (c) and (f) 1.5_\%S-QAS. Cell size distributions of these materials: (g) 0.5_\%S-QAS, (h) 1_\%S-QAS and (i) 1.5_\%S-QAS.

Table 6

Characteristics of the bimodal cellular structure of the cellular materials produced at $10 \mathrm{MPa}$ from the three particle contents used in this work.

\begin{tabular}{|c|c|c|c|c|c|c|}
\hline \multirow[t]{2}{*}{ Particle content (wt $\%$ ) } & \multicolumn{3}{|l|}{ Main population } & \multicolumn{3}{|c|}{ Secondary population } \\
\hline & $\begin{array}{l}\text { Volume fraction } \\
(\%)\end{array}$ & $\begin{array}{l}\text { Cell size } \phi \\
(\mathrm{nm})\end{array}$ & $\begin{array}{l}\text { Standard deviation } S D \\
(\mathrm{~nm})\end{array}$ & $\begin{array}{l}\text { Volume fraction } \\
(\%)\end{array}$ & $\begin{array}{l}\text { Cell size } \phi \\
(\mu \mathrm{m})\end{array}$ & $\begin{array}{l}\text { Standard deviation } S D \\
(\mu \mathrm{m})\end{array}$ \\
\hline 0.5 & 56.5 & 470 & 227 & 43.5 & 6.5 & 5.0 \\
\hline 1 & 62.7 & 395 & 226 & 37.3 & 4.7 & 3.4 \\
\hline 1.5 & 77.8 & 314 & 172 & 22.2 & 7.8 & 7.5 \\
\hline
\end{tabular}

Cell nucleation density and the cell size (of the nanometric cells) as a function of the saturation pressure are shown in Fig. 12. Two different behaviours can be appreciated for the cell nucleation density (Fig. 12a). On the one hand, cell nucleation density of PMMA increases as saturation pressure increases, as seen in the previous results. On the other hand, all the blends produced with S-QAS present an almost constant cell nucleation density for the three saturation pressures used, which proves that the heterogeneous 
a)

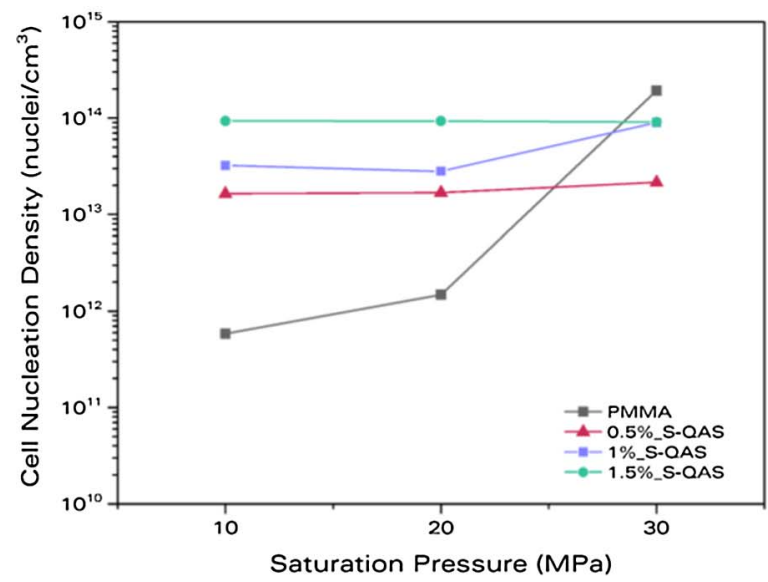

b)

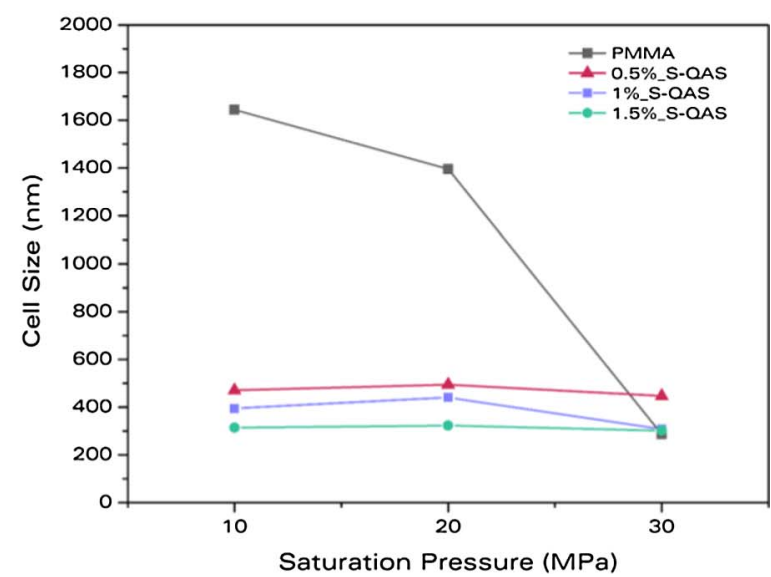

Fig. 12. (a) Cell nucleation density and (b) cell size as a function of the saturation pressure for the blends containing sepiolite S-QAS and the pure PMMA.

nucleation mechanism predominates over homogeneous nucleation in these materials. Moreover, cell nucleation density is a function of the particle content: higher particle contents produce higher nucleation densities. For instance, at $10 \mathrm{MPa}$ of saturation pressure, cell nucleation density increases in a factor of 2 when increasing the sepiolite content from $0.5 \mathrm{wt} \%$ to 1 wt $\%$, and in a factor of 6 when the S-QAS content is $1.5 \mathrm{wt} \%$.

Fig. 12b shows that the average cell size of the three materials with S-QAS remains almost constant with pressure, oppositely to the behaviour of the neat PMMA, for which the average cell size decreases with pressure. In fact the three materials present cell sizes below $500 \mathrm{~nm}$. In addition, 1.5\%_S-QAS presents the lowest cell sizes, whereas 0.5 \%S-QAS shows the highest. Thus, there is a reduction of the cell size when the particle content increases (Table 5), which matches with the higher cell densities found for higher particle contents.

The main conclusion of this section is that the amount of sepiolites determines the effective cell nucleation and the final cell size, the cell nucleation density being higher for higher particle contents. This increase of the nucleation density as the particle content increases is a consequence of the heterogeneous nucleation mechanism: larger particle contents imply more nucleation sites where nuclei can appear. Larger cell densities yield to smaller cell sizes. This result is commonly observed in systems filled with nanoparticles $[17,22,23,27]$. Besides, the volume fraction occupied by the nanometric cell increases as sepiolite content increases. Assuming the well dispersed sepiolites are in the nanocellular volume fraction, this result will imply that higher particle contents lead to better dispersions. In fact, an increase in the particle content in a factor of 3 leads to an increase in the nucleation density of 6 , indicating a slightly better dispersion for a filler loading of $1.5 \mathrm{wt} \%$, in agreement with the largest volume fraction of nanocellular pores.

\subsubsection{Effect of the foaming temperature}

To evaluate the influence of the foaming temperature three different foaming temperatures has been employed, $80{ }^{\circ} \mathrm{C}, 100{ }^{\circ} \mathrm{C}$ and $110^{\circ} \mathrm{C}$. In this case saturation pressure will be kept constant at $10 \mathrm{MPa}$. It has been previously observed that at $80{ }^{\circ} \mathrm{C}$ the blends containing S-QAS produce bimodal cellular structures with relative densities around 0.27 (see Tables 3 and 5). The relative densities

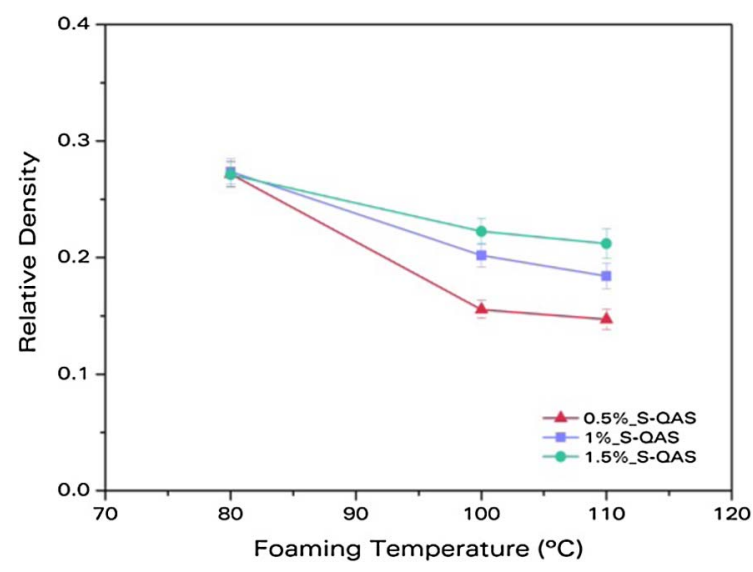

Fig. 13. Relative density as a function of the foaming temperature. 

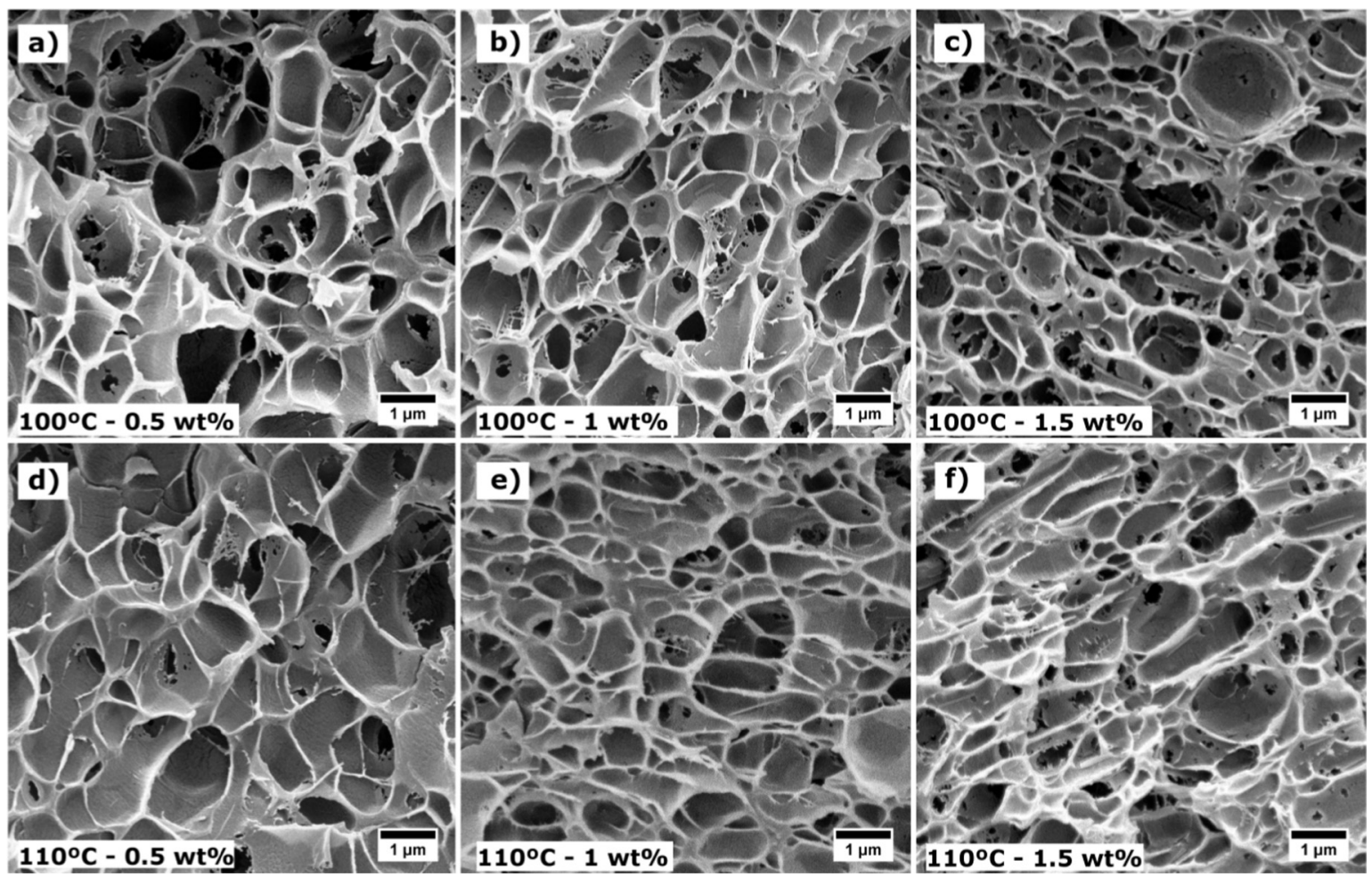

Fig. 14. First row: Samples foamed at $100^{\circ} \mathrm{C}$. Second row: Samples foamed at $110{ }^{\circ} \mathrm{C}$. (a) and (d) 0.5 \% $\%$ S-QAS; (b) and (e) $1 \_\% S-Q A S$; (c) and (f) $1.5_{-} \% S-Q A S$.

obtained at $100{ }^{\circ} \mathrm{C}$ and $110{ }^{\circ} \mathrm{C}$ are displayed in Fig. 13. This plot shows that, for a constant saturation pressure, relative density decreases as foaming temperature increases for the three particle contents studied. All the samples had initially the same amount of gas absorbed (same $\mathrm{T}_{\mathrm{g} \text {,eff }}$ ) but now the final foaming temperature is different. The higher the foaming temperature, the largest

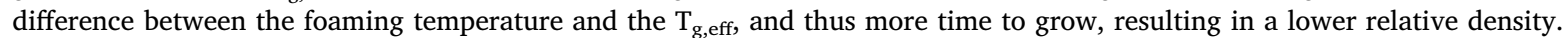

However, the reduction in density obtained is different for each material. Whereas the material containing $0.5 \mathrm{wt} \%$ of S-QAS shows a decrease in density in a factor of 1.8 from $80{ }^{\circ} \mathrm{C}$ to $110{ }^{\circ} \mathrm{C}$, in the blend with $1.5 \mathrm{wt} \%$ of sepiolite S-QAS this reduction is only in a factor of 1.3. The conclusion is that the addition of nanoparticles limits the minimum density that can be achieved with this processing route. This can be due to the higher viscosity of the blends with higher particle contents.

SEM micrographs of the samples foamed at higher temperatures are shown in Fig. 14. Note that these images correspond to the previously-called nanocellular structure (main population) and not the microcellular population (recall that there was a bimodal cell size distribution in all the materials with S-QAS). Compared to Fig. 11, the images in Fig. 14, which correspond to cellular materials produced at higher foaming temperatures, show a clear increase of the cell size.

a)

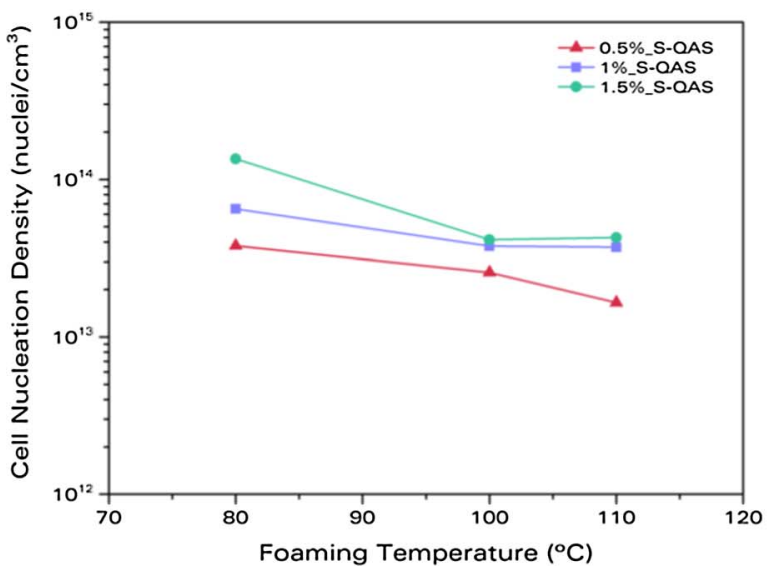

b)

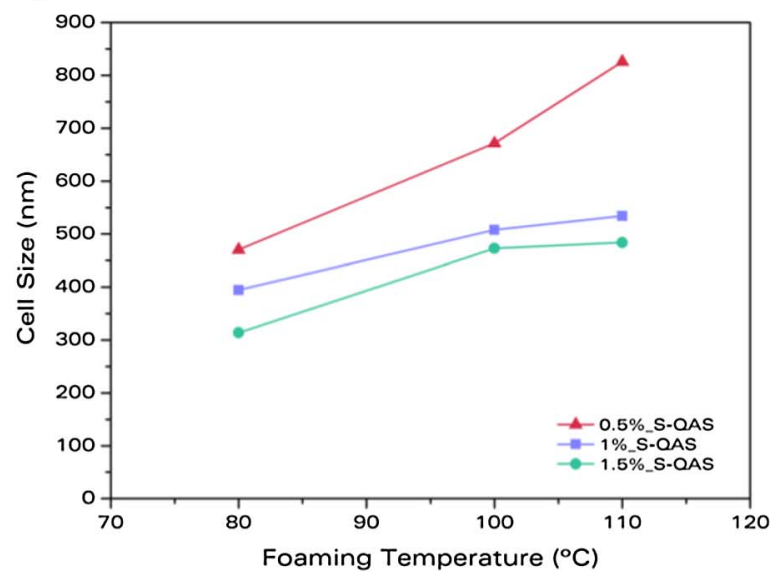

Fig. 15. (a) Cell nucleation density and (b) cell size as a function of the saturation pressure. 
Fig. 15 shows the evolution of the cell nucleation density (a) and the cell size (b) of the main population as a function of the foaming temperature. Both cell nucleation density and cell size present important changes when foaming temperature is increased. On the one hand, cell nucleation density decreases as the foaming temperature increases for the three materials under study (Fig. 15a). Thus, there is a reduction in the number of cells in the cellular material, meaning that cell wall rupture phenomena (coalescence events) take place as temperature increases. For instance, for 1.5\%_S-QAS, cell nucleation density is reduced from $1.4 \cdot 10^{14}$ nuclei $/ \mathrm{cm}^{3}$ at $80^{\circ} \mathrm{C}$ to $4.3 \cdot 10^{13}$ nuclei $/ \mathrm{cm}^{3}$ at $110^{\circ} \mathrm{C}$, that is, cell nucleation density is halved when the foaming temperature is increased in $30^{\circ} \mathrm{C}$.

As a result of cell coalescence, the average cell size increases as foaming temperature increases (Fig. 15b). The increase in cell size implies that some of the cellular materials produced with these high foaming temperatures cannot be considered nanocellular polymers anymore. Cellular materials produced with a content of $0.5 \mathrm{wt} \%$ of S-QAS present cell sizes of around 670 and $830 \mathrm{~nm}$ at $100{ }^{\circ} \mathrm{C}$ and $110{ }^{\circ} \mathrm{C}$, respectively, above the nanocellular threshold indicated in the introduction of this paper ( $\left.>500 \mathrm{~nm}\right)$. However, materials with the highest S-QAS content still belong to the nanometric range, with cell sizes of 470 and $480 \mathrm{~nm}$ for foaming temperatures of $100{ }^{\circ} \mathrm{C}$ and $110{ }^{\circ} \mathrm{C}$ and they have low relative densities $(0.21)$.

The main conclusion of this section is that the relative density can be indeed reduced by increasing the foaming temperature, but in return cell size increases due to cell coalescence. This result is not in agreement with those found in the work of Martin-de Leon et al. [13], which analyses the effect of the foaming temperature in a pure PMMA matrix. They found that cell size remained constant despite the density reduction. Again the role of the sepiolites is crucial to understand the differences between the two systems. In the blends with sepiolites, particle aggregates (and individual particles themselves) are probably larger than cell wall thickness and struts. For this reason, they favour cell coalescence as the cell wall thickness is reduced when the density decreases and due to this these systems are more prone to coalescence than the pure polymer.

\section{Conclusions}

Nanocellular polymeric materials based on PMMA and containing nanometric sepiolites have been produced by means of a gas dissolution foaming process. Nanocomposites with different particle types and contents were produced by extrusion and compression moulding. Cell sizes in the range of $300-500 \mathrm{~nm}$ and cell densities of the order of $10^{13}-10^{14}$ nuclei/ $\mathrm{cm}^{3}$ have been obtained. These nanocellular polymers, with relative densities around 0.3 , can be produced in a wide range of saturation pressures (from 10 to $30 \mathrm{MPa}$ ) using low particle contents (between 0.5 and $1.5 \mathrm{wt} \%$ ) and low foaming temperatures $\left(80{ }^{\circ} \mathrm{C}\right)$.

Among the three types of particles employed in this work, it has been identified that only the sepiolite modified with a quaternary ammonium salt (S-QAS) can be used as a nucleating agent for PMMA. The addition of this particle produces bimodal cellular structures, with micro and nanometric cells, the nanometric population being predominant. An increase in the content of sepiolites leads to a reduction of the cell size in the nanometric population, as well as to an increase of the cell nucleation density. Besides, as particle content increases the fraction of nanometric cells increases. At low pressures, where the pure polymer produces microcellular materials, the PMMA/sepiolite blends produce bimodal nanocellular structures. A particle content of $1.5 \mathrm{wt} \%$ increases nucleation in a factor of 160 compared to the pure polymer foamed under the same conditions $\left(10 \mathrm{MPa}, 80^{\circ} \mathrm{C}\right)$, whereas cell size decreases in a factor of 5. As pressure increases, the nucleation in the pure polymer increases and cell size decreases (homogeneous nucleation). However, this behaviour is not observed in the blends with the sepiolites modified with a quaternary ammonium salt. For these systems the influence of the saturation pressure (and thus of the amount of gas absorbed by the polymer) is not significant, and this is a consequence of a predominant heterogeneous nucleation. Relative density can be reduced by increasing the foaming temperature, but at the expense of increasing the cell size of the nanocellular population. Cell coalescence is significant at a foaming temperature of $100{ }^{\circ} \mathrm{C}$, probably due to the existence of particle aggregates which favour cell wall ruptures.

In conclusion, in this work nanocellular PMMA materials have been produced using for the first time sepiolites as nucleating agent. The production of these new materials requires not demanding process parameters (medium pressure and room temperature) and low particle contents, which make them attractive for mass scale production. Further research will determine the properties, future applications and possibilities of these promising materials.

\section{Acknowledgments}

Financial support from FPU grant FPU14/02050 (V. Bernardo) from the Spanish Ministry of Education and Junta of Castile and Leon grant Q4718001C (J. Martín-de León) is gratefully acknowledged. Financial assistance from MINECO, FEDER, UE (MAT201569234-R) and the Junta de Castile and Leon (VA011U16) are gratefully acknowledged. We would also like to thank the company Tolsa (Madrid, Spain) for supplying the sepiolites of this study.

\section{References}

[1] B. Notario, J. Pinto, M.A. Rodriguez-Perez, Nanoporous polymeric materials: a new class of materials with enhanced properties, Prog. Polym. Sci. 78-79 (2016) 93-139.

[2] B. Notario, J. Pinto, M.A. Rodríguez-Pérez, Towards a new generation of polymeric foams: PMMA nanocellular foams with enhanced physical properties, Polymer 63 (2015) 116-126.

[3] D. Miller, V. Kumar, Microcellular and nanocellular solid-state polyetherimide (PEI) foams using sub-critical carbon dioxide II. Tensile and impact properties, Polymer 52 (2011) 2910-2919.

[4] S. Costeux, $\mathrm{CO}_{2}$-blown nanocellular foams, J. Appl. Polym. Sci. 131 (2014) 41293(1)-41293(16). 
[5] B. Notario, J. Pinto, E. Solorzano, J.A. de Saja, M. Dumon, M.A. Rodriguez-Perez, Experimental validation of the Knudsen effect in nanocellular polymeric foams, Polymer 56 (2015) 57-67.

[6] M. Knudsen, The Kinetic Theory of Gases, Methuen, London, 1934.

[7] L. Li, L. Schulte, L.D. Clausen, K.M. Hansen, G.E. Jonsson, S. Ndoni, Gyroid nanoporous membranes with tunable permeability, ACS Nano 5 (2011) 7754-7766.

[8] J. Pinto, M. Dumon, M.A. Rodriguez-Perez, R. Garcia, C. Dietz, Block copolymers self-assembly allows obtaining tunable micro or nanoporous membranes or depth filters based on PMMA; fabrication method and nanostructures, J. Phys. Chem. C 118 (2014) 4656-4663.

[9] G.Q. Lu, X.S. Zhao, Nanoporous Materials - An Overview, Nanoporous materials: Science and engineering, Imperial College Press, London, 2004.

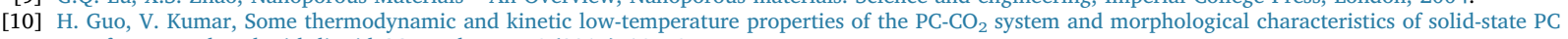
nanofoams produced with liquid $\mathrm{CO}_{2}$, Polymer 56 (2015) 46-56.

[11] H. Guo, A. Nicolae, V. Kumar, Solid-state microcellular and nanocellular polysulfone foams, J. Polym. Sci. B: Polym. Phys. 53 (2015) 975-985.

[12] H. Guo, A. Nicolae, V. Kumar, Solid-state poly(methyl methacrylate) (PMMA) nanofoams. Part II: low-temperature solid-state process space using $\mathrm{CO}_{2}$ and the resulting morphologies, Polymer 70 (2015) 231-241.

[13] J. Martin de-Leon, V. Bernardo, M.A. Rodriguez-Perez, Low density nanocellular polymers based on PMMA produced by gas dissolution foaming: fabrication and cellular structure characterization, Polymers 8 (2016) 1-16.

[14] V. Bernardo, J. Martín-de Leon, M.A. Rodriguez-Perez, Production and characterization of nanocellular polyphenylsulfone foams, Mater. Lett. 178 (2016) $155-158$.

[15] H. Guo, V. Kumar, Solid-state poly(methyl methacrylate) (PMMA) nanofoams. Part I: low-temperature $\mathrm{CO}_{2}$ sorption, diffusion, and the depression in PMMA glass transition, Polymer 57 (2015) 157-163.

[16] V.I. Kalikmanov, Nucleation Theory, Springer, 2013.

[17] S. Costeux, L. Zhu, Low density thermoplastic nanofoams nucleated by nanoparticles, Polymer 54 (2013) $2785-2795$.

[18] Y.H. Lee, C.B. Park, K.H. Wang, HDPE-Clay nanocomposite foams blown with supercritical $\mathrm{CO}_{2}$, J. Cell. Plast. 41 (2005) $487-502$.

[19] C. Forest, P. Chaumont, P. Cassagnau, B. Swoboda, P. Sonntag, CO2 nano-foaming of nanostructured PMMA, Polymer 58 (2015) $76-87$.

[20] J. Pinto, M. Dumon, M. Pedros, J. Reglero, M.A. Rodriguez-Perez, Nanocellular $\mathrm{CO}_{2}$ foaming of PMMA assisted by block copolymer nanostructuration, Chem. Eng. J. 243 (2014) 428-435.

[21] J. Pinto, J.A. Reglero-ruiz, M. Dumon, M.A. Rodriguez-Perez, Temperature influence and $\mathrm{CO}_{2}$ transport in foaming processes of poly (methyl methacrylate) block copolymer nanocellular and microcellular foams, J. Supercritical Fluids 94 (2014) 198-205.

[22] W. Zhai, J. Yu, L. Wu, W. Ma, J. He, Heterogeneous nucleation uniformizing cell size distribution in microcellular nanocomposites foams, Polymer 47 (2006) $7580-7589$.

[23] H. Janani, M.H.N. Famili, Investigation of a strategy for well controlled inducement of microcellular and nanocellular morphologies in polymers, Polym. Eng. Sci. 50 (2010) 1558-1570.

[24] J. Yang, L. Huang, Y. Zhang, F. Chen, P. Fan, M. Zhong, S. Yeh, A new promising nucleating agent for polymer foaming: applications of ordered mesoporous silica particles in polymethyl methacrylate supercritical carbon dioxide microcellular foaming, Ind. Eng. Chem. Res. 52 (2013) 14169-14178.

[25] Y. Fujimoto, S.S. Ray, M. Okamoto, A. Ogami, K. Yamada, K. Ueda, Well-controlled biodegradable nanocomposite foams: from microcellular to nanocellular, Macromol. Rapid Commun. 24 (2003) 457-461.

[26] L. Urbanczyk, C. Calberg, C. Detrembleur, C. Jérôme, M. Alexandre, Batch foaming of SAN / clay nanocomposites with sc CO 2 : a very tunable way of controlling the cellular morphology, Polymer 51 (2010) 3520-3531.

[27] S. Siripurapu, J.M. Desimone, S.A. Khan, R.J. Spontak, N. Carolina, N. Carolina, Controlled foaming of polymer films through restricted surface diffusion and the addition of nanosilica particles or $\mathrm{CO}_{2}$-philic surfactants, Macromolecules 38 (2005) 2271-2280.

[28] M. Liu, M. Pu, H. Ma, Preparation, structure and thermal properties of polylactide/sepiolite nanocomposites with and without organic modifiers, Compos. Sci. Technol. 72 (2012) 1508-1514.

[29] N. García, J. Guzman, E. Benito, A. Esteban-Cubillo, E. Aguilar, J. Santaren, P. Tiemblo, Surface modification of sepiolite in aqueous gels by using methoxysilanes and its impact on the nanofiber dispersion ability, Langmuir 27 (2011) 3952-3959.

[30] N.H. Huang, Z.J. Chen, J.Q. Wang, P. Wei, Synergistic effects of sepiolite on intumescent flame retardant polypropylene, Express Polym. Lett. 4 (2010) 743-752.

[31] E. Bilotti, H.R. Fischer, T. Peijs, Ȧ. Si, Polymer nanocomposites based on needle-like sepiolite clays: effect of functionalized polymers on the dispersion of nanofiller, crystallinity, and mechanical properties, J. Appl. Polym. Sci. 107 (2008) 1116-1123.

[32] Y. Zheng, Y. Zheng, Study on sepiolite-reinforced polymeric nanocomposites, J. Appl. Polym. Sci. 99 (2006) $2163-2166$.

[33] P. Lu, The effects of different grafted clays on thermal properties of their PMMA composites, Polym.-Plast. Technol. Eng. 50 (2011) $1541-1545$.

[34] J.A. Igualada, J.L. Feijoo, United States Patent Application Igualada et al. 2015, Patent US 2015/0337103.

[35] J. Santaren, A. Alvarez, A. Esteban-Cubillo, B. Notario, D. Velasco, M.A. Rodriguez-Perez, Improving the cellular structure and thermal conductivity of PS Foams by using sepiolites, In Foams 2012 (2012) 1-5.

[36] J.M. Chem, M. Frydrych, C. Wan, R. Stengler, U.O. Kelly, B. Chen, Structure and mechanical properties of gelatin/sepiolite nanocomposite foams, J. Mater. Chem. 30 (2011) 9103-9111.

[37] D. Killeen, M. Frydrych, B. Chen, Porous poly (vinyl alcohol)/ sepiolite bone scaffolds: preparation, structure and mechanical properties, Mater. Sci. Eng. C 32 (2012) 749-757.

[38] A. Alvarez, J. Santaren, A. Esteban-Cubillo, P. Aparicio, E. Galan, A. Singer (Eds.), Development in Palygorskite-Sepiolite Research, Elsevier, 2011.

[39] E. Ruiz-Hitzky, Molecular access to intracrystalline tunnels of sepiolite, J. Mater. Chem. 11 (2001) 86-91.

[40] D. Garcia-Lopez, J.F. Fernandez, J.C. Merino, J. Santaren, J.M. Pastor, Effect of organic modification of sepiolite for PA 6 polymer/organoclay nanocomposites, Compos. Sci. Technol. 70 (2010) 1429-1436.

[41] V. Kumar, N.P. Suh, A process for making microcellular parts, Polym. Eng. Sci. 30 (1990) 1323-1329.

[42] J. Zhao, A.B. Morgan, J.D. Harris, Rheological characterization of polystyrene-clay nanocomposites to compare the degree of exfoliation and dispersion, Polymer 46 (2005) 8641-8660.

[43] E. Laguna-Gutierrez, R. Van Hooghten, P. Moldenaers, M.A. Rodriguez-Perez, Effects of extrusion process, type and content of clays, and foaming process on the clay exfoliation in HMS PP composites, J. Appl. Polym. Sci. 132 (2015) 42430(1)-42430(14).

[44] C. Forest, P. Chaumont, P. Cassagnau, B. Swoboda, P. Sonntag, Nanofoaming of PMMA using a batch $\mathrm{CO}_{2}$ process: influence of the PMMA viscoelastic behaviour, Polymer 77 (2015) 1-9.

[45] J. Pinto, E. Solo, M.A. Rodriguez-perez, J.A. De Saja, Characterization of the cellular structure based on user-interactive image analysis procedures, J. Cell. Plast. 49 (2013) 555-575.

[46] V. Kumar, Process Synthesis for Manufacturing Microcellular Thermoplastic Parts, Massachusetts Institute of Technology, 1988.

[47] C.A. Mandarim-de-Lacerda, Stereological tools in biomedical research, Ann. Braz. Acad. Sci. 75 (2003) $469-486$.

[48] C. Saiz-Arroyo, M.A. Rodriguez-Perez, J.I. Velasco, J.A. de Saja, Influence of foaming process on the structure - properties relationship of foamed LDPE / silica nanocomposites, Compos. B 48 (2013) 40-50.

[49] J.E. Weller, V. Kumar, Solid State Microcellular PC Foams I, Polym. Eng. Sci. 47 (2007) 21-25.

[50] Y.D. Hwang, S.W. Cha, The relationship between gas absorption and the glass transition temperature in a batch microcellular foaming process, Polym. Test. 21 (2002) 269-275.

[51] P. Alessi, A. Cortesi, I. Kikic, F. Vecchione, Plasticization of polymers with supercritical carbon dioxide : experimental determination of glass-transition temperatures, J. Appl. Polym. Sci. 88 (2003) 2189-2193.

[52] Z. Zhang, Y.P. Handa, An in situ study of plasticization of polymers by high-pressure gases, J. Polym. Sci. 36 (1998) $977-982$.

[53] D. Rende, L.S. Schadler, R. Ozisik, Controlling foam morphology of poly(methyl methacrylate) via surface chemistry and concentration of silica nanoparticles and supercritical carbon dioxide process parameters, J. Chem. 2013 (2013).

[54] K. Goren, L. Chen, L.S. Schadler, R. Ozisik, Influence of nanoparticle surface chemistry and size on supercritical carbon dioxide processed nanocomposite foam morphology, J. Supercrit. Fluids 51 (2010) 420-427. 